\title{
Electronic states at dislocations and metal silicide precipitates in crystalline silicon and their role in solar cell materials
}

\author{
Michael Seibt • Reda Khalil • Vitaly Kveder • \\ Wolfgang Schröter
}

Received: 2 April 2008 / Accepted: 24 November 2008 / Published online: 24 December 2008

(C) Springer-Verlag 2008

\begin{abstract}
Predominant dislocation types in solar silicon are dissociated into $30^{\circ}$ - and $90^{\circ}$-partials with reconstructed cores. Besides shallow 1D-band localized in their strain field and a quasi-2D band at the stacking fault connecting the two partials, the existence of several intrinsic core defects with deep lying levels has been demonstrated by electron spin resonance. The majority of core defects occur in nonequilibrium situations and, with the exception of a small EPRsignal assigned to a reconstruction defect, vanish after careful annealing above $800^{\circ} \mathrm{C}$. There is good evidence now that part of deep levels observed in dislocated silicon is associated with impurities, especially with transition metal impurities. Electron-hole-pair recombination at a dislocation mainly runs via its shallow bands and is strongly increased by impurities bound to its core or in the strain field. The concentration of these impurities can be reduced by gettering processes to such a low level that radiative recombination at dislocations yields a luminescence efficiency of $0.1 \%$ at room temperature.

A quite coherent picture has emerged for metal impurity precipitation in silicon. Early stages of precipitation in defect-free silicon are characterised by kinetically selected metastable defects forming as a result of large chemical
\end{abstract}

M. Seibt $(\bowtie) \cdot$ R. Khalil · V. Kveder · W. Schröter

IV. Physikalisches Institut der Georg-August Universität

Göttingen, Friedrich-Hund-Platz 1, 37077 Göttingen, Germany

e-mail: seibt@ph4.physik.uni-goettingen.de

Present address:

R. Khalil

Faculty of Science, Physics Department, Benha University, 13518 Benha, Egypt

V. Kveder

Institute of Solid State Physics RAS, 142432 Chernogolovka, Russia driving forces for precipitation. Such defects are associated with deep level spectra which show the properties of extended multielectron defects. The evolution of the system to energetically more favourable configurations proceeds via ordinary particle coarsening but also via internal ripening, a process reminiscent of the above-mentioned metastable defects. Electronically, the defects evolve into metal-like inclusions which in general seem to act as strong recombination centers for minority carriers. In the presence of dislocations metastable defects quickly transform into equilibrium structures in the course of precipitation or do not form at all. In the presence of several metal impurities silicide precipitates which can be described as solid solutions of the respective metal atoms are observed, which is at least qualitatively in accord with ternary phase diagrams. Like single-metal silicide precipitates, strong minority carrier recombination is also typical for those multi-metal silicide particles.

PACS 61.72.uf $\cdot 61.72 . \mathrm{Yx} \cdot 61.72 . \mathrm{S} \cdot 71.55 . \mathrm{Cn}$

\section{Introduction}

Compared to state-of-the-art silicon materials used in highlevel microelectronics present-day crystalline silicon for mainstream photovoltaic applications usually contains a high density of defects [1]. The majority of crystalline silicon for photovoltaics is multicrystalline materials produced by casting or ribbon growth techniques. Independent of the specific growth technique, such materials inherently contain grain boundaries and dislocations. Dislocations are inhomogeneously distributed leading to virtually dislocation-free regions and local dislocation densities up to $10^{6}-10^{7} \mathrm{~cm}^{-2}$ in the same material. In addition, their effect on the electrical properties of crystalline silicon, as measured, e.g., by 
the minority carrier diffusion length or lifetime maps, is not directly related to their local density.

This has been taken as evidence that charge carrier recombination at dislocations is not governed by intrinsic properties but strongly influenced by processing conditions and impurities [2]. In fact, interaction of dislocations with point defects of intrinsic or extrinsic origin is known to considerably change the deep level spectrum of dislocations [3]. Besides oxygen which is incorporated into silicon from quartz crucibles during growth, transition metal impurities unintentionally introduced during crystal growth or subsequent processing are obvious candidates for many reasons. The latter are their ubiquitous presence in technical environments, their extraordinarily fast diffusion in silicon, and their general tendency to introduce deep levels into the bandgap of silicon [4]. Their segregation in the strain field around dislocations and in particular their possible binding to the dislocation core will considerably change the deep level spectrum of dislocations and may dominate the electrical behavior of the latter [5].

Furthermore, dislocations may serve as heterogeneous nucleation sites for metal silicide particles once the solid solution of metal impurities gets supersaturated during cooling from high temperature [5]. Again, such precipitates are known to act as strong recombination sites and may dominate the recombination when decorating dislocations $[2,6]$. Early stages of metal silicide precipitation in dislocationfree silicon are known to be related to nonequilibrium structures which are kinetically selected in order to facilitate fast relaxation of extraordinarily large driving forces occurring in undercooled solutions of transition metal atoms in silicon [7-9]. The created defects are frequently associated with deep band-like states that are characterised by fast internal transitions between states constituting the multi-electron system $[8,10]$.

The defects transform into energetically more favorable configurations which are accompanied by a modification of their deep level spectrum. In this stage, their recombination behavior has been described in terms of internal Schottky contacts $[6,11,12]$. It is interesting to note that in all cases dislocations play a decisive role in particular in the early stages of precipitation, which explains the fact that kinetically selected nonequilibrium structures have never been observed in dislocated silicon. Apparently, these structures never form there or quickly transform into energetically more favorable configurations in the course of precipitation.

Recently, the more practical case of the simultaneous presence of various transition metal impurities has returned into focus of experimental research [13]. Multi-metal silicides have been observed in multicrystalline silicon for solar cell applications as a result of co-precipitating transition metal impurities. The electronic properties of multi-metal precipitates have not yet been studied systematically.
In this work, we summarize current understanding of electronic states at extended defects in crystalline silicon, in particular dislocations and metal silicide precipitates. These seemingly separated topics are closely related due to the strong interaction of dislocations and transition metal impurities, so that consideration of the atomic structure of dislocations and silicide precipitates are also included where appropriate. Sect. 2 is devoted to deep states at dislocations. Starting from the basic atomistic structure, we briefly describe the properties of shallow one-dimensional (1D) bands at glide dislocations which result from the strain field and hence are an intrinsic property of dislocations (Sect. 2.1). Deep levels at dislocations and their concerted action with the $1 \mathrm{D}$ bands are the ingredients to quantitatively describe excess charge carrier recombination at dislocations (Sect. 2.2). Spectroscopic investigations of deep levels at dislocations are summarized in Sect. 2.3, where the interaction of point defects with dislocations is discussed in some detail. The special case of transition metal impurities and the related topic of impurity gettering will conclude Sect. 2 .

The topic of Sect. 3 is the formation and electronic structure of metal silicide precipitates in silicon. After a brief introduction into the general properties of transition metal silicides, nonequilibrium configurations forming as a result of extraordinarily large chemical driving forces for precipitation are described in Sect. 3.1.1 for nickel and copper in silicon. Deep band-like and localized states related to these defects and their possible structural origin are depicted in Sect. 3.1.2 followed by short summaries of the electronic and structural properties of large silicide precipitates (Sect. 3.2) and those heterogeneously formed at dislocations (Sect. 3.3). Section 3.4 is devoted to the currently investigated topic of multimetal precipitation in silicon, which is clearly driven by technical requirements in silicon photovoltaics, and also involves some basic questions on coprecipitation. The paper is finished by a summary and a critical outlook.

\section{Dislocations in silicon}

\subsection{Shallow states at dislocations}

In silicon crystals dislocations glide in $\{111\}$ glide planes and their Burgers vectors are of type $\frac{a}{2}\langle 110\rangle$. However, there are two possible $\{111\}$ sets of glide systems for dislocations: the shuffle set when the dislocation core is between the widely spaced $\{111\}$-planes and the glide set when the core is lying between the narrowly spaced $\{111\}$-planes. The dislocations of these two sets have different core structures and must have considerably different electronic properties. Dislocations of the glide set, which form by plastic deformation at high temperature, can dissociate into two parallel Shockley partial dislocations with a stacking fault ribbon 
between them. The geometry of the dangling bonds in their cores is such that forming new covalent bonds between the dangling bonds (bond reconstruction) more than compensates the associated increase of elastic energy (see [14] for a more detailed discussion).

Dislocations of the shuffle set cannot dissociate into partials, and the dangling bonds of the core are nearly normal to the glide plane. In this case the bond reconstruction needs so large atomic displacement that it seems to be energetically unfavorable. Shuffle set dislocations have been reported recently for low-temperature deformation of silicon [15].

Fortunately, most of dislocations generated in $\mathrm{Si}$ at a temperature above $600^{\circ} \mathrm{C}$ by either macroscopic or microscopic plastic deformation are screw and $60^{\circ}$ dislocations of the glide set, which are dissociated into $90^{\circ}$ and $30^{\circ}$ Shockley partial dislocations with reconstructed cores. Theory predicts that ideal straight and clean segments of such dislocation are not associated with any deep electronic states in the band gap of silicon (see [3] for review). They are, however, associated with relatively shallow one-dimensional electronic energy bands (1D-bands) and a filled quasi-2D band caused by the elastic strain field and the Shockley stacking fault separating the two partials of dissociated gld ie dislocations, respectively. The empty one splits down from the conduction band with its bottom at $E_{\mathrm{C}}-E_{\mathrm{De}}$, and the occupied one splits up from the valence band with its top at $E_{\mathrm{V}}+E_{\mathrm{Dh}}$, where $E_{\mathrm{C}}$ and $E_{\mathrm{V}}$ denote the edges of the conduction and valence band, respectively. Theory has shown that the strain field of the partial dislocations pushes the stacking fault states deeper into the bandgap [16].

Figure 1 illustrates how the cores of the $90^{\circ}$ - and a $30^{\circ}$ partial can be reconstructed. The RD is a defect of reconstruction, which contains a dangling bond and must produce a deep donor and an acceptor level in the band gap. At elevated temperature the reconstruction defects can move along the dislocation and can annihilate pairwise. It is evident that the concentration of dangling bonds related to reconstruction defects should critically depend on the thermal history of the silicon material and it should be possible to reduce their concentration by a proper thermal annealing. All available experimental data support the theoretical predictions that reconstruction of partial dislocations in $\mathrm{Si}$ is energetically favorable. For example, EPR measurements show that the concentration of paramagnetic dangling bonds can be sometimes quite significant for dislocations introduced at $T<700^{\circ} \mathrm{C}$ and is strongly reduced after annealing at $T>800^{\circ} \mathrm{C}$ [17-19].

The energy positions $E_{\mathrm{De}}$ and $E_{\mathrm{Dh}}$ of the edges of 1D-bands for $60^{\circ}$ dislocations were estimated from the photo-excitation spectrum of the electric dipole spin resonance (EDSR) in 1D-bands [20] of straight dislocations in $\mathrm{Si}$. It was found that $\left(E_{\mathrm{C}}-E_{\mathrm{De}}\right) \simeq\left(E_{\mathrm{Dh}}-E_{\mathrm{V}}\right) \simeq$ 80-85 meV. These values for $\left(E_{\mathrm{C}}-E_{\mathrm{De}}\right)$ and $\left(E_{\mathrm{Dh}}-E_{\mathrm{V}}\right)$

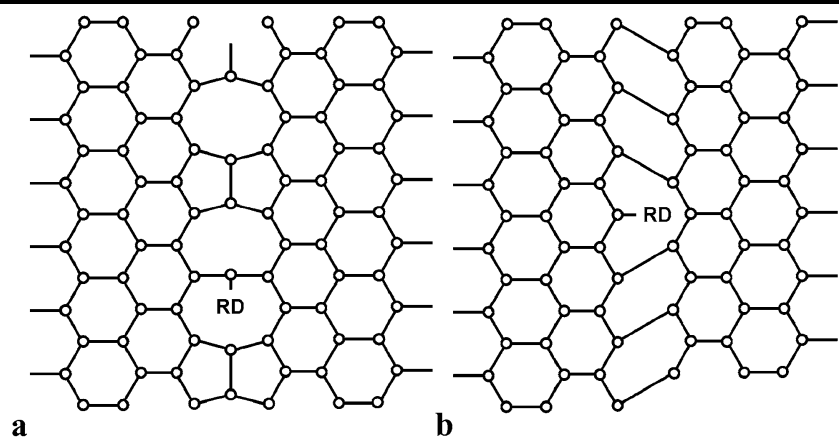

Fig. 1 Core view in the (111) glide plane of $30^{\circ}$ (left) and $90^{\circ}$ (right) Shockley partial dislocations in their reconstructed states; RD denote reconstruction defects that are mobile at high temperature and possibly give rise to deep states at dislocations

are quite close to the values $\left(E_{\mathrm{Dh}}-E_{\mathrm{V}}\right) \simeq 65 \mathrm{meV}$ and $\left(E_{\mathrm{C}}-E_{\mathrm{De}}\right) \simeq 85 \mathrm{meV}$ calculated in [21] from the temperature dependencies of the conductivity in specially prepared p- and n-type silicon samples with dislocations. Similar results, $\left(E_{\mathrm{Dh}}-E_{\mathrm{V}}\right) \simeq 70 \mathrm{meV}$ and $\left(E_{\mathrm{C}}-E_{\mathrm{De}}\right) \simeq 80 \mathrm{meV}$ have been also obtained in [22] from measurements of temperature dependence of microwave conductivity in plastically deformed $\mathrm{n}$ - and p-type silicon and from DLTS [23].

For dislocations with such not very deep 1D bands one cannot expect a high recombination activity since the radius of electronic wave functions in the direction perpendicular to dislocation is not small enough to allow complete overlapping of the electron and hole wave functions in $k$-space.

In EBIC, the variation of the current at a $\mathrm{p}-\mathrm{n}$ junction or at a Schottky contact, $I$, resulting from nonequilibrium electrons and holes generated by the electron beam, is measured, when the specimen area of interest is scanned. The values of $I$ at the dislocation, $I_{\text {disl }}$, and away from it, $I_{0}$, are used to define the contrast $C_{\text {disl }}=\left(I_{0}-I_{\text {disl }}\right) / I_{0}$ of single dislocation, which is directly related to recombination rate at this dislocation. Indeed, the EBIC measurements [24, 25] show that in cases where dislocations seem to be sufficiently "clean," their recombination activity is very small and nearly not observable at room temperature. This allows us to suppose that the recombination rate caused by direct transitions between $1 \mathrm{D}$ bands $D_{\mathrm{e}}$ and $D_{\mathrm{h}}$ is quite small.

\subsection{Deep states at dislocations}

At the same time, it was found that dislocations in silicon often exhibit very high EBIC contrast equivalent to a strongly reduced minority carrier lifetime [24-30]. The only way to explain existing experimental data is to suppose that in addition to the $1 \mathrm{D}$-bands, $D_{\mathrm{e}}$ and $D_{\mathrm{h}}$, real dislocations can also have deep localized (0-D) electronic states, originating from

- "native" (or intrinsic) core defects like reconstruction defects, jogs, and core defects caused by vacancies and selfinterstitials incorporated into dislocation core, or 
- impurity atoms in the dislocation core or in the strain field of dislocation in the form of very narrow $(\simeq 1 \mathrm{~nm})$ clouds.

Please note, that-since dislocations are topological defects-the electronic energy levels of impurities incorporated into the dislocation core in general should differ significantly from the energy levels of the same impurities incorporated as individual atoms within the bulk. Recent calculations for substitutional copper in the dislocations core confirm this basic argument [31]. In contrast to the number of states of one-dimensional bands, concentrations of deep electronic states related to core defects and impurities strongly depend on the material's thermal history and can vary in a very wide range. This statement is strongly supported by numerous experimental data obtained mainly by EBIC and deep level transient spectroscopy (DLTS), which permits to measure the concentrations of electrons and holes captured by dislocation-related deep states.

Before DLTS data are summarized, we briefly discuss the main features of minority carrier recombination at dislocation. Let us consider for certainty n-type $\mathrm{Si}$, so that electrons are majority carriers, and their concentration $\mathrm{n}$ is higher than the concentration of holes $\mathrm{p}$, which are minority carriers in this case (see Fig. 2).

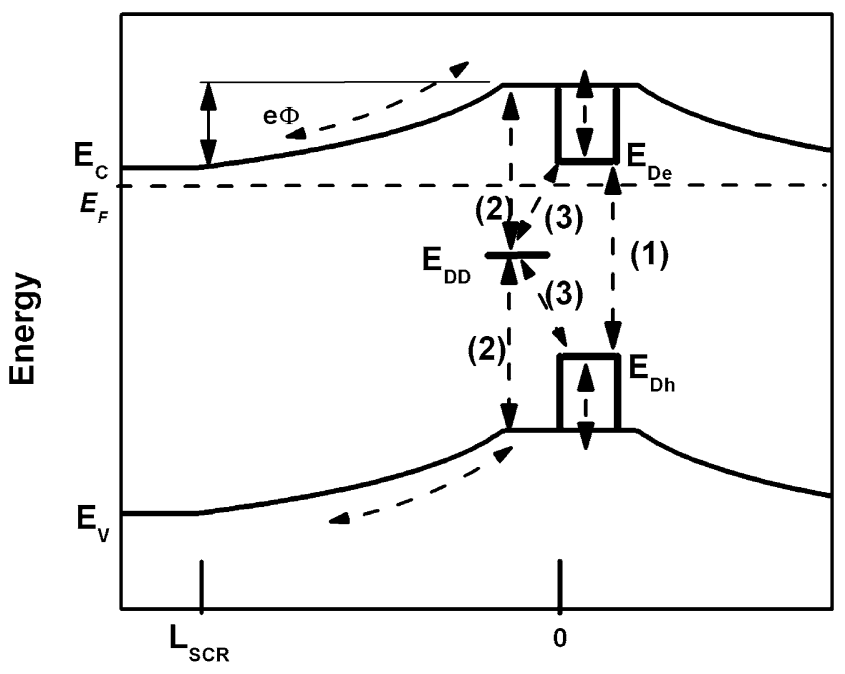

Distance from dislocation core, $r$

Fig. 2 Charge carrier recombination at dislocations. The important feature is the Coulomb barrier $\Phi$ appearing around a dislocation due to its line charge caused by majority carriers-electrons in this figure-captured to the dislocation states. For clean dislocations, the recombination rate is determined by direct recombination of electrons and holes captured by the $1 \mathrm{D}$ dislocation bands $E_{\mathrm{De}}, E_{\mathrm{Dh}}$ (path (1)). In the presence of defects with a deep energy level $E_{\mathrm{DD}}$, recombination occurs directly via the deep level (path (2)), and, in addition, the carriers captured to 1D-bands recombine by path (3) via this deep level [2]; $E_{\mathrm{C}}, E_{\mathrm{V}}$ refer to the edges of the conduction and valence band, respectively, and $E_{\mathrm{F}}$ indicates the position of the Fermi level. In addition, the radius $L_{\mathrm{SCR}}$ of the space charge layer around dislocations is indicated
When considering the capture of free electrons and holes and the occupation statistics of electronic energy states at dislocation, we should first of all remember that majority carriers captured by electronic states at the dislocation create a Coulomb band-bending $e \Phi$ around it (see Fig. 2). As a result, the capture rate of free electrons to such states is reduced approximately by the factor $\exp \left(-e \Phi / k_{\mathrm{B}} T\right)$ and finally limits the total equilibrium occupation of dislocation states by electrons. At the same time, this electrostatic potential is attractive for minority carriers and accelerates their capture and recombination at dislocations.

The interaction of free charge carriers with the dislocation line charge is an important feature, which has been investigated in detail in the literature and has been taken into account in all models for recombination at dislocations (see, for example, [2, 32-35]). The exact calculation of $e \Phi$ is a difficult problem (for details, see [3]), but in many cases it can be approximated by the simple formula

$e \Phi=\frac{e^{2} N_{\text {tot }}}{2 \pi \varepsilon \varepsilon_{0}}\left(\ln N_{\text {tot }} L_{\text {scr }}-0.5\right)$,

where $N_{\text {tot }}$ is the total dislocation charge per unit length (the concentration of electrons or holes captured to all dislocation energy states), $\varepsilon$ is the dielectric permittivity of $\mathrm{Si}$, and $n_{\mathrm{d}}$ is the concentration of shallow donors. Equation (1) assumes that the screening radius $L_{\mathrm{scr}}$ of the electric field around the dislocation is of about

$L_{\mathrm{scr}}=\sqrt{\frac{N_{\mathrm{tot}}}{\pi n_{\mathrm{d}}}}$.

As a result, the total dislocation charge $N_{\text {tot }}$ per unit length is limited by the screening potential rather than the total number of states $N_{\mathrm{DD}}$ per unit length. The presence of excess minority carriers results in a nonequilibrium occupation of dislocation energy states, and the dislocation electrostatic potential $e \Phi$ is reduced, roughly like $e \Phi \simeq k_{\mathrm{B}} T \ln (n / p)$, which is a consequence of the fact that fluxes of electron and holes to the dislocation have to balance each other in stationary conditions.

Another important feature of recombination at dislocations is the significant influence of 1D-bands on the recombination process due to electronic transitions between 1D-bands $E_{\mathrm{De}}, E_{\mathrm{Dh}}$ via the deep localized states $E_{\mathrm{DD}}$ caused by overlapping of their wave functions (recombination path (3) in Fig. 2). It should be noted that these transitions have to be taken into account for a proper description of the recombination activity of dislocations [2].

Transitions between 1D-bands (path (1) in Fig. 2) are associated with a relatively small recombination rate, i.e., the recombination activity of "clean" dislocation is small unless the temperature is below about $90 \mathrm{~K}$. The recombination can be drastically enhanced by the presence of even a 
small concentration of deep levels due to impurity atoms or core defects at the dislocation. In this case recombination occurs in several steps: capture of free electrons and holes to 1D-bands, their motion along dislocation, then capture from the 1D band to the deep states, and finally recombination. The model permits not only to explain experimentally observed dependencies of the recombination rate on temperature and excitation level but also to estimate the concentration of deep level defects at dislocations [2].

Figure 3a shows, as an example, the EBIC contrast of dislocations which is proportional to the recombination rate of minority carriers at dislocations, calculated for $T=120 \mathrm{~K}$ and $T=290 \mathrm{~K}$ depending on the number $N_{\mathrm{DD}}$ of deep defects. It was assumed that the sample is n-type with a doping density of $n_{\mathrm{d}}=2 \times 10^{15} \mathrm{~cm}^{-3}$ and that dislocation defects have a single acceptor level at $E_{\mathrm{DD}}=E_{\mathrm{C}}-0.45 \mathrm{eV}$ with a capture cross-section $\sigma_{\mathrm{e}}=2 \times 10^{-15} \mathrm{~cm}^{2}$ for electrons and $\sigma_{\mathrm{h}}=10^{-13} \mathrm{~cm}^{2}$ for holes, the hole concentration was $p=10^{13} \mathrm{~cm}^{-3}$. A steep linear increase of the recombination rate with increasing of $N_{\mathrm{DD}}$ is observed in the range

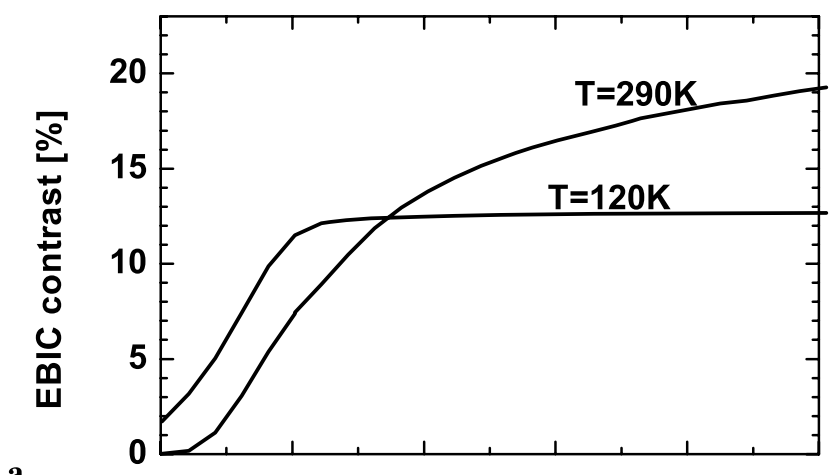

$\mathbf{a}$

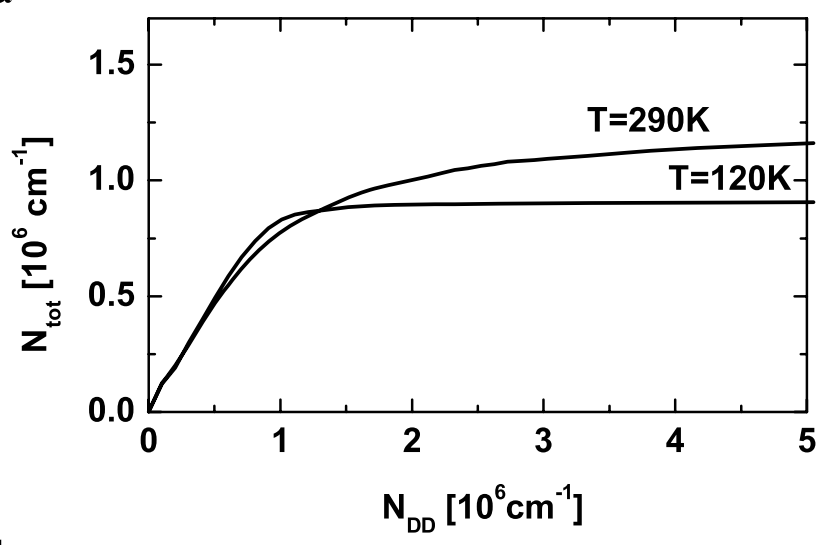

b

Fig. 3 Calculated dependencies on the number $N_{\mathrm{DD}}$ of deep defects on dislocation (per $\mathrm{cm}$ of dislocation length) of: (a) recombination activity of dislocation (proportional to its EBIC contrast) at $T=120 \mathrm{~K}$ and $T=290 \mathrm{~K}$; (b) density of electrons captured to deep defects; calculations were done for n-type material (doping of $2 \times 10^{15} \mathrm{~cm}^{-3}$ ), a single dislocation-related acceptor level at $E_{\mathrm{DD}}=E_{\mathrm{C}}-0.45 \mathrm{eV}$ with capture cross-sections $\sigma_{\mathrm{e}}=2 \times 10^{-15} \mathrm{~cm}^{2}$ for electrons and $\sigma_{\mathrm{h}}=10^{-13} \mathrm{~cm}^{2}$ for holes, the minority carrier concentration is $p=10^{13} \mathrm{~cm}^{-3}$ of $N_{\mathrm{DD}}<10^{6} \mathrm{~cm}^{-1}$, which is mainly due to the increase of the negative dislocation line charge caused by electrons captured by defects. The Coulomb potential $e \Phi$ is attractive for holes and accelerates their capture and hence the recombination at the dislocation. In this range, the minority carrier lifetime is much shorter when deep defects are located at dislocations compared to the case where dislocations are clean but the same number of deep defects are distributed randomly in a bulk, i.e., accumulation of impurities at dislocations has a deleterious effect on the diffusion length. The high recombination rate at deep defects located at dislocations is mainly due to the acceleration of recombination by intermediate capture of electrons and holes to 1D-bands, having a large capture radius, and by the attractive Coulomb potential of negatively charged dislocations. Please note that for calculations, (1) has been used, which typically is an upper limit for the true potential around dislocations [36]. More accurate calculations give qualitatively similar results. Quantitatively, however, curves depend on chosen parameter values and on the model used to calculate the barrier around dislocations.

At very high concentration of deep defects at dislocations $N_{\text {DD }}>(2-3) \times 10^{6} \mathrm{~cm}^{-1}$, further increase of the recombination rate with increasing $N_{\mathrm{DD}}$ tends to saturate because the occupation of deep defects by electrons becomes smaller and smaller in this regime (see Fig. 3b) since it is strongly limited by the Coulomb potential $e \Phi$, which is now growing proportionally to $k_{\mathrm{B}} T \cdot \log \left(N_{\mathrm{DD}}\right)$. Also the diffusion of holes to dislocations becomes an additional limiting factor for recombination. Please note that, if the concentration of deep defects is larger than a certain value, their accumulation at dislocations results in a larger lifetime compared to the case of a homogeneous distribution. In this regime, impurity accumulation at dislocations has a beneficial effect on the minority carrier diffusion length. At high injection levels, the increase of the minority carrier concentration results in a decreasing Coulomb potential $e \Phi$, which in turn leads to a decreasing recombination efficiency of dislocations.

\subsection{Experimental observation of deep defect states at dislocations by DLTS}

\subsubsection{DLTS on extended defects}

The deep level transient spectroscopy (DLTS) is widely used for the investigation of deep states at extended defects. By registration of the capacitance transients of a Schottky contact, $C(t)$, it allows one to measure the electron emission kinetics from defects inside the depletion region under the Schottky contact. Since the initial occupation of defects by electrons (or holes) is adjustable by variation of the capture time $t_{\mathrm{p}}$ preceding the emission period $t_{\mathrm{e}}$, the capture kinetic of the defect can be also investigated. This makes 


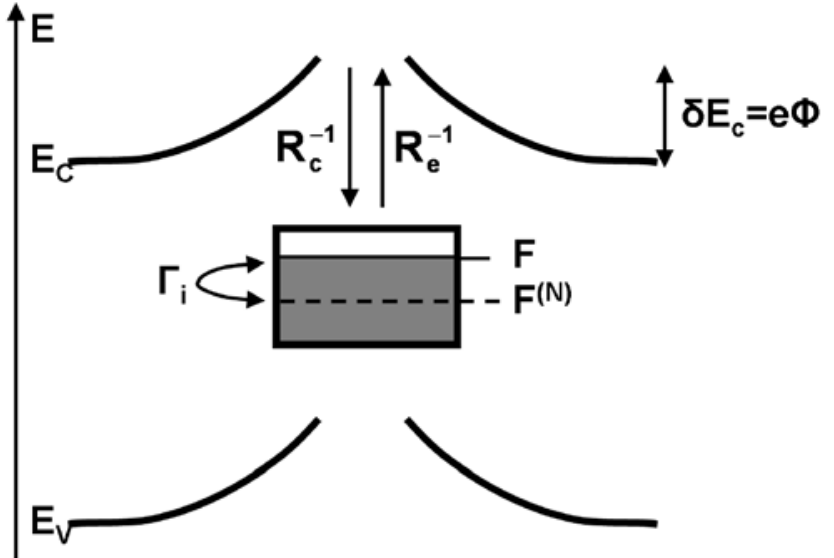

Fig. 4 Schematic scheme showing the important quantities needed to describe electron capture and emission at an extended defect: the electrostatic barrier $\delta E_{\mathrm{c}}=e \Phi(F)$, the total occupation $F$ of defect states, electron capture and emission rates $R_{\mathrm{c}}$ and $R_{\mathrm{e}}$, respectively, and $\Gamma_{\mathrm{i}}$ denoting the time necessary to establish an equilibrium distribution in the deep level system for fixed occupation. The quantity $F^{(N)}$ denotes occupation of the neutral defect, i.e., $\Phi\left(F=F^{(N)}\right)=0$, subsequently referred to as the "neutral occupation"

DLTS a powerful tool to distinguish defect states located at extended defects from isolated point defects in the bulk by measuring the dependence of spectra on capture time duration $t_{\mathrm{p}}$ [37-39].

Figure 4 schematically shows the important quantities needed to describe electron capture and emission at an extended defect: the electrostatic potential $\delta E_{\mathrm{c}}=e \Phi(F)$, the total occupation $F$ of defect states, electron capture and emission rates $R_{\mathrm{c}}$ and $R_{\mathrm{e}}$, respectively, and $\Gamma_{\mathrm{i}}$ denoting the time necessary to establish an equilibrium distribution in the deep level system for fixed occupation. The quantity $F^{(N)}$ denotes the neutral occupation, i.e., $\Phi\left(F=F^{(N)}\right)=0$. The two limiting cases of localized $\left(\Gamma_{\mathrm{i}} \gg R_{\mathrm{c}}^{-1}\right.$ and $\left.R_{\mathrm{e}}^{-1}\right)$ and band-like $\left(\Gamma_{\mathrm{i}} \ll R_{\mathrm{c}}^{-1}\right.$ and $\left.R_{\mathrm{e}}^{-1}\right)$ states can be distinguished on the basis of DLTS since they lead to qualitatively different dependencies of spectra on $t_{\mathrm{p}}$ [37]. Experiments on dislocation-related deep levels in silicon have shown localized states, whereas band-like states have been observed for metal silicide precipitates in silicon (see Sect. 3.1.2).

For localized states, the kinetic equation for the occupation $f_{k}$ of a state with energy $E_{k}$ is

$$
\begin{aligned}
\frac{d f_{k}}{d t}= & \sigma \cdot v_{\mathrm{th}} n\left(1-f_{k}\right) e^{-\frac{e \Phi(F)}{k_{\mathrm{B}} T}} \\
& -\sigma \cdot v_{\mathrm{th}} N_{\mathrm{C}} e^{-\frac{E_{\mathrm{C}}-E_{k}}{k_{\mathrm{B}} T}} \cdot f_{k} .
\end{aligned}
$$

Here $\sigma$ is the capture cross-section, $v_{\text {th }}$ and $n$ the mean thermal velocity and density of free electrons, respectively, and $N_{\mathrm{C}}$ the effective density of states in the conduction band. The common capture barrier $e \Phi$ results in a logarithmic dependence of $F$, the total occupation of defects $F=\sum_{k} f_{k}$,

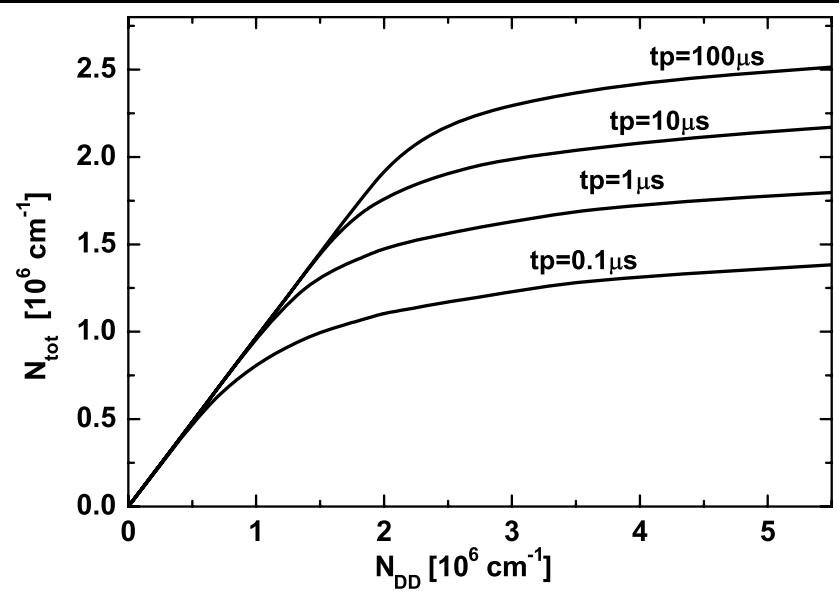

Fig. 5 Calculated dependence of the number of electrons captured to deep defects on dislocations on the total number $N_{\text {DD }}$ of these deep defects. This quantity is proportional to the amplitude of the DLTS signal for a filling pulse with different duration $t_{\mathrm{p}}$ (calculations were done for n-type silicon with doping of $2 \times 10^{15} \mathrm{~cm}^{-3}$ and dislocation defects have a single acceptor level at $E_{\mathrm{DD}}=E_{\mathrm{C}}-0.45 \mathrm{eV}$ with capture cross-section $\sigma_{\mathrm{e}}=2 \times 10^{-15} \mathrm{~cm}^{2}$; the DLTS frequency is $v=28 \mathrm{~Hz}$, the temperature is $T=226 \mathrm{~K}$ )

on $t_{\mathrm{p}}$, while for point defects, this dependence is exponential. So, the observation of a logarithmic dependence of the DLTS line amplitude on $t_{\mathrm{p}}$ indicates that this DLTS line corresponds to states localized at dislocation (or other extended defects).

However, the logarithmic behavior with $t_{\mathrm{p}}$ can be observed only when the density of deep defects $N_{\mathrm{DD}}$ is high enough to create a large Coulomb band bending $e \Phi \gg$ $k_{\mathrm{B}} T$ [40]. This is illustrated in Fig. 5, which shows that the logarithmic dependence of DLTS signal on $t_{\mathrm{p}}$ can be expected when the total number of states at dislocation is typically higher or about $10^{6} \mathrm{~cm}^{-1}$. In this case the density of states spectrum can be obtained from simultaneous fit of theoretically simulated DLTS spectra to experimental DLTS spectra measured in a sufficiently wide range of refilling pulse durations $t_{\mathrm{p}}$ and repetition frequencies $v$. The behavior of the DLTS signal with variation of $t_{\mathrm{p}}$ also allows detecting internal transitions between defect states at extended defects that may happen if the density-of-states is high enough [38, 41], see Sect. 3.1.2.

\subsubsection{DLTS on dislocated silicon}

Deep dislocation-related energy levels have been intensively investigated by DLTS (see, for example, [23, 37-39, 4144]), and we know already quite a lot about their properties. However, the exact origin of the defects at dislocations responsible for all these well-known dislocation-related deep energy levels detected by DLTS is not yet completely clear. As it was already mentioned, the concentration of deep localized electronic states, related to core defects and impurities at dislocations, depends strongly on sample history and 


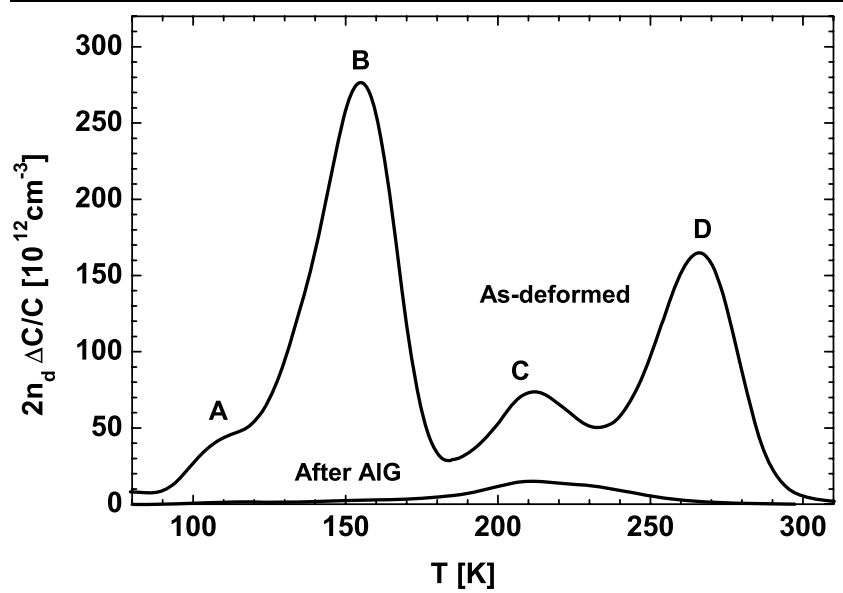

Fig. 6 DLTS spectra of n-FZ-Si sample $\left(n_{\mathrm{d}}=n=2 \times 10^{15} \mathrm{~cm}^{-3}\right)$ deformed at $750^{\circ} \mathrm{C}$ by compression along [123] (one glide plane) to a dislocation density $N_{\mathrm{D}} \simeq 3 \times 10^{8} \mathrm{~cm}^{-2}$ measured in the as-deformed state and after aluminum gettering $\left(850^{\circ} \mathrm{C}, 30 \mathrm{~min}\right)$. DLTS conditions are $v=29 \mathrm{~Hz}, U_{\mathrm{b}}=U_{\mathrm{p}}=5 \mathrm{~V}, t_{\mathrm{p}}=0.1 \mathrm{~ms}$

can vary in a very wide range. It may be controlled to a certain extent by annealing. It is known that annealing at $T>800^{\circ} \mathrm{C}$ leads to a strong reduction of the concentration of some of the core defects, which have been introduced by plastic deformation at lower temperatures. Apparently, local equilibrium of intrinsic dislocation core defects is in some way re-established at those temperatures, although dislocations as nonequilibrium defects survive. As soon as the dislocations are forced to move, the point defect equilibria are again disturbed [3].

As an example, Fig. 6 shows a typical DLTS spectrum of deep dislocation-related acceptor states detected in n-type silicon deformed at $750^{\circ} \mathrm{C}$ to a dislocation density $N_{\mathrm{D}}$ of about $3 \times 10^{8} \mathrm{~cm}^{-2}$. The DLTS spectrum in the as-deformed sample mainly consists of several overlapping nonuniformly broadened lines $\mathrm{A}$ at about $E_{\mathrm{C}}-0.19 \mathrm{eV}$, B at about $E_{\mathrm{C}}-0.3 \mathrm{eV}, \mathrm{C}$ at $E_{\mathrm{C}}-(0.37-0.43) \mathrm{eV}$, and $\mathrm{D}$ at $E_{\mathrm{C}}-0.54 \mathrm{eV}$, well known in literature (here, we have adopted the notation of [40]). Line broadening is typical for dislocation-related deep defects and can be usually in the order of $10-50 \mathrm{meV}$. All these lines are always observed for dislocations introduced at $T<800^{\circ} \mathrm{C}$. They show all characteristic features of deep localized states at extended defects, like the logarithmic dependence of the signal amplitude on $t_{\mathrm{p}}$. The total concentration $N_{\mathrm{DD}}$ of states associated with lines B, C, and D estimated from numerical fitting is of about (2-3) $\times 10^{6} \mathrm{~cm}^{-1}$ for the as-deformed sample shown in Fig. 6. In some cases it can be even higher.

The defects B and D are known to be thermally unstable, and their concentration can be strongly reduced by annealing at $T>800^{\circ} \mathrm{C}$. Hence, they may correspond to some metastable intrinsic core defects. In particular, the D-line might be related to dangling bond defects at dislocations observed in such kind of samples by the EPR technique. It is

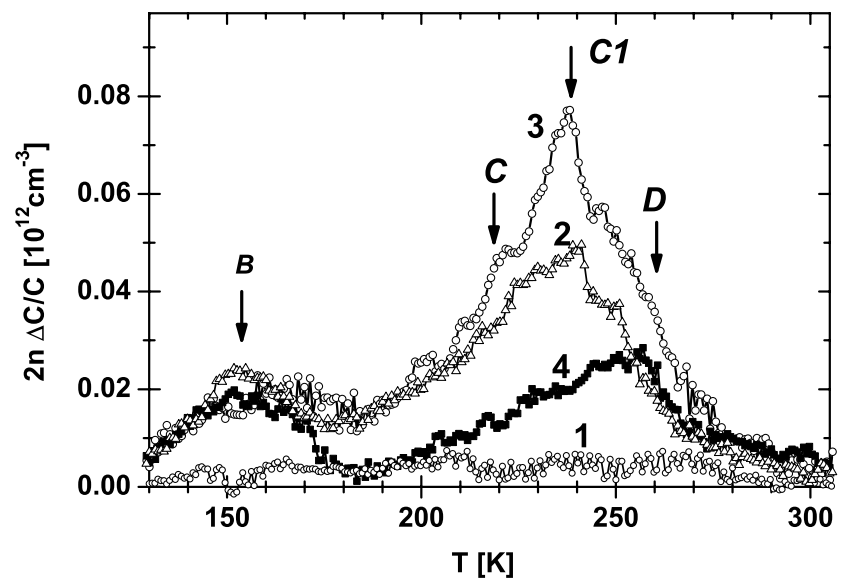

Fig. 7 DLTS spectra in the $\mathrm{n}-\mathrm{Cz}-\mathrm{Si}$ sample with $5 \times 10^{4} \mathrm{~cm}^{-2}$ dislocations introduced at $600^{\circ} \mathrm{C}$ by 4 -point bending. (1) after dislocation motion at $600^{\circ} \mathrm{C}$ with a speed of $10 \mu \mathrm{m} / \mathrm{min}$ at a load $90 \mathrm{MPa}$ up to dislocation loops diameter $L=510 \mu \mathrm{m}$; (2) after additional keeping of this sample at $600^{\circ} \mathrm{C}$ under load $30 \mathrm{MPa}$ (dislocation speed 2 $\mu \mathrm{m} / \mathrm{min}$ ) during 6 hours (loops diameter $L=1740 \mu \mathrm{m}$ ); (3) after additional keeping of this sample at $600^{\circ} \mathrm{C}$ under load $30 \mathrm{MPa}$ (dislocation speed $2 \mu \mathrm{m} / \mathrm{min}$ ) during 3 hours (loop diameter $L=2430 \mu \mathrm{m}$ ); (4) after additional dislocation motion at $600^{\circ} \mathrm{C}$ with a speed of $10 \mu \mathrm{m} / \mathrm{min}$ at a load $90 \mathrm{MPa}$ during 10 minutes (up to loop diameter $2630 \mu \mathrm{m}$. DLTS conditions are: $U_{\mathrm{b}}=5 \mathrm{~V}, U_{\mathrm{p}}=4 \mathrm{~V}, t_{\mathrm{p}}=0.1 \mathrm{~ms}, v=28.6 \mathrm{~Hz}$ [41]

generally observed that the C-line remains nearly unaffected by usual thermal annealing or even increases in some cases. At the same time, the concentration of defects associated with the $\mathrm{C}$-line can be drastically reduced by aluminium gettering (AlG) [45]. Therefore one can suppose that they are related to impurities at dislocations, which can be reduced in concentrations by external gettering processes. This may be taken as a strong hint that transition metal impurities play an important role for the C-line. As one can see in Fig. 6, indeed, $\mathrm{AlG}$ at $850^{\circ} \mathrm{C}$ results in a strong reduction not only of B- and D-lines but also of the C-line (see Sect. 2.4 for a more detailed discussion).

Additional arguments supporting the hypothesis that defects associated with the C-line correspond to some impurity atoms at dislocations were recently demonstrated by Kveder et al. [41]. They have studied how dislocation-related DLTS signals are influenced by the velocity of dislocations during 4-point deformation at $600^{\circ} \mathrm{C}$ in n-type $\mathrm{Cz}-\mathrm{Si}$ samples with a small density (about $5 \times 10^{4} \mathrm{~cm}^{-2}$ ) of long individual dislocations loops. The dislocation loops were generated at $600^{\circ} \mathrm{C}$ from indentation pits which were subsequently etched out to prevent further generation of dislocations. The DLTS signal from the same dislocations was measured after sequential deformation steps at $600^{\circ} \mathrm{C}$ at different loads forcing dislocations to move with different velocity (Fig. 7).

It turned out that the DLTS C- and C1-lines appear with high amplitude for a small dislocation speed ( $v_{\text {dis }} \simeq$ $2 \mu \mathrm{m} / \mathrm{min}$ ), whereas the concentration of the related defects strongly decreases for $v_{\text {dis }} \simeq 10 \mu \mathrm{m} / \mathrm{min}$. The most proba- 
ble explanation of this experiment is the following: When the dislocation velocity is smaller than some critical value, they collect impurities resulting in an increase of the DLTS C- and C1-lines. However, if the dislocations are forced to move with a high velocity, impurity atoms will not be able to follow the dislocations. The latter will then loose nearly all impurity atoms accumulated before as has been shown by calculations [46]. A related phenomenon has previously been reported where a correlation of the dislocation C-line to the distance the dislocations have moved during deformation $[47,48]$ has been observed.

\subsection{Transition metal impurities: candidates for accumulation at dislocations}

In intrinsic silicon 3d-elements are predominantly dissolved on interstitial sites of tetragonal symmetry $\left(T_{\mathrm{d}}\right.$-sites). They diffuse much faster than impurities dissolved on substitutional sites, since they do not need a vacancy or silicon interstitial as diffusion vehicle. Within the 3d-row there is a significant variation of the migration enthalpy, which decreases from $1.8 \mathrm{eV}$ for $\mathrm{Ti}_{i}$ to about $0.4 \mathrm{eV}$ for $\mathrm{Co}_{i}$ and $0.2 \mathrm{eV}$ for $\mathrm{Cu}_{i}$. As a consequence, $\mathrm{Ti}_{i}$ and $\mathrm{V}_{i}$ can be easily kept in solution even by moderate quenching, $\mathrm{Cr}_{i}, \mathrm{Mn}_{i}$, and $\mathrm{Fe}_{i}$ in the absence of extended defects can be kept as isolated species or in pairs with dopant atoms by rapid quenching. Their electrical influence, especially on the minority carrier lifetime, is determined by their electronic levels in the silicon band gap and the associated capture cross sections. These parameters are known for the 3d-elements in silicon with the exception of those for $\mathrm{Co}_{i}, \mathrm{Ni}_{i}$, and $\mathrm{Cu}_{i}$. Diffusion of these three impurities is so fast that they have escaped electrical characterization so far. They may form complexes with dopant atoms, in which case their electrical influence again is described by their levels and capture cross sections. However, if these impurities precipitate and act as silicide particles or segregate at other extended defects like dislocations or oxide particles, their electrical effects are rather involute.

Accumulation of point defects at dislocations can be roughly divided into three fundamentally different types: (i) segregation in the dislocation strain field, (ii) (chemical) binding to the dislocation core, and (iii) accumulation close to dislocations as a result of fast equilibration of intrinsic point defects there. The latter effect is restricted to those impurities that are mainly dissolved on substitutional sites but diffuse via the interstitial species like, e.g., gold and platinum in silicon. Note that in this case the accumulation would be a transient phenomenon. Segregation in the dislocation strain field is due to an elastic interaction with impurities, which has its main contribution from the size effect, i.e., the difference of the (covalent) radii of the impurity and the host lattice [49]. Since the edge component of dislocations provides both dilatation and compression field, negative and positive misfit will result in an attractive interaction.
It has been shown by numerical simulations that such clouds of impurities collected by dislocations can account for not only the logarithmic capture kinetics but also the asymmetrical broadening of DLTS lines which is frequently observed experimentally $[3,37]$. The main ingredients for this result are the inhomogeneous distribution of point defects in the dislocation strain field adequately viewed as a very narrow point defect cloud, and a strain-induced relative shift of the deep level and the band to which the predominant emission occurs. An asymmetrically broadened DLTS line has been observed as the dominant signal after diffusion of nickel into plastically deformed silicon and subsequent quenching [45]. The signal is very similar to the dislocation C-line family and can be reduced by external gettering. Gold indiffusion into n-type silicon has also been reported to result in a DLTS line close to the C-line family [50], which seems to be incompatible with results reported in [51,52]. Binding of transition metal impurities to the dislocation core has recently gained some interest both experimentally and theoretically. The main questions to be answered refer to the electronic structure of impurity species in the dislocation core and their binding energies there. The former is related to the recombination activity of such decorated dislocations although, e.g., the EBIC contrast of dislocation does not sensitively depend on the position of the associated deep levels [2]. The latter is important when binding and dissociation kinetics are to be modelled in view of "cleaning" contaminated dislocations by external gettering techniques. A recent theoretical study [31] shows that substitutional copper exhibits a negative U-like ordering of the associated donor and acceptor levels in the cores of partial dislocations. In addition, a high binding energy between 1.5 and $2 \mathrm{eV}$ has been calculated by these authors. For gold in silicon, which is mainly dissolved on substitutional sites, such properties would lead to an almost complete accumulation of gold in the dislocation cores even at elevated temperature. Recent experiments for gold in silicon show an increased total concentration of gold in dislocated silicon below about $1000^{\circ} \mathrm{C}$ which corroborates this view [53].

\subsection{Gettering and passivation: dislocation luminescence}

From the results summarized above it may be inferred that deep levels at dislocations and the related high recombination activity are not unavoidable properties but mainly originate from intrinsic core defects that can be eliminated by proper annealing and passivation, and from some impurity atoms that can be eliminated by a proper gettering and passivation. The term gettering refers to a class of technological processes used to remove metal impurities from active regions of silicon devices and is an integral part of solar cell manufacturing $[4,54]$. Following this line, an experimental study was performed $[55,56]$, where the effect of aluminum 
(AlG) and phosphorus diffusion gettering (PDG) and hydrogen passivation on the DLTS signal of dislocations and on the dislocation-related luminescence was investigated.

After deformation of $\mathrm{n}$ - and p-type $\mathrm{FZ}-\mathrm{Si}$ samples at $750^{\circ} \mathrm{C}$ to a dislocation density of $(3-5) \times 10^{8} \mathrm{~cm}^{-2}$ DLTS spectra showed several overlapping asymmetrically broadened dislocation-related lines well known in literature (see, e.g., Fig. 6). The linear density $N_{\mathrm{DD}}$ of these states was determined as about $(2-3) \times 10^{6} \mathrm{~cm}^{-1}$. Subsequent AlG resulted in a very strong reduction of the DLTS signal to a concentration of $N_{\mathrm{DD}} \simeq 2 \times 10^{5} \mathrm{~cm}^{-1}$, which could be further reduced by PDG and hydrogen passivation to $N_{\text {DD }}<10^{5} \mathrm{~cm}^{-1}$. Such a reduction of deep defect concentration $N_{\mathrm{DD}}$, detected by DLTS, is accompanied by a very strong reduction of nonradiative recombination at dislocations and in a dramatic (by many orders of magnitude) increase of dislocation-related D1-luminescence efficiency near room temperature. It was shown that pnjunctions prepared on such gettered and passivated samples emit the $1.55 \mu \mathrm{m}$ light corresponding to dislocation-related D1-luminescence, with an external efficiency of about $0.1 \%$ at room temperature. Hence, properly cleaned dislocations can be considered as a suitable candidate for fabrications of in-chip light emitters, strongly demanded by microelectronic industry.

\section{Metal silicide precipitates in silicon}

A supersaturated solid solution of a single fast diffusing transition metal impurity in silicon finally relaxes into precipitates consisting of the silicon-richest silicide in the respective binary phase diagram. These silicides are of type $M \mathrm{Si}_{2}$ for the late $3 \mathrm{~d}$ transition elements $(M=\mathrm{Fe}, \mathrm{Co}, \mathrm{Ni})$ with the exception of copper, where the metal-rich $\mathrm{Cu}_{3} \mathrm{Si}$ is the intermetallic compound in equilibrium with the solid solution of copper in silicon. A striking feature is a nearly perfect volume fit of the disilicide phases to silicon, whereas the misfit between $\mathrm{Cu}_{3} \mathrm{Si}$ and silicon is large (Table 1). It should be noted that, for copper and palladium, dislocation formation is an integral part of the precipitation process, whereas for iron, cobalt, and nickel, secondary defects are not observed unless large particles have formed that lead to dislocation punching during cooling as a result of considerably different thermal expansion coefficients of the disilicides and silicon [57].

\subsection{Early stages of precipitation}

Before summarizing previous results on early stages of iron, cobalt, nickel, and copper silicide precipitation some unique properties of the disilicides shall be considered. $\mathrm{CoSi}_{2}$, $\mathrm{NiSi}_{2}$, and $\gamma-\mathrm{FeSi}_{2}$ crystallize in the cubic $\mathrm{CaF}_{2}$-structure
Table 1 Properties of silicides for the heavy $3 \mathrm{~d}$ transition elements, denoted as $M$ and the $4 \mathrm{~d}$ element palladium; the relative volume change $\Delta V / V$ is calculated per formula unit; $\alpha$ and $\beta$ : number of silicon self-interstitials and vacancies, respectively, emitted per precipitating metal atom assuming a strain-free precipitate; SF denotes stacking fault

\begin{tabular}{lllll}
\hline$M$ & Silicide & $\frac{\Delta V}{V}[\%]$ & $\alpha-\beta$ & Secondary defects \\
\hline $\mathrm{Fe}$ & $\alpha-\mathrm{FeSi}_{2}$ & -5.5 & -0.11 & - \\
& $\beta-\mathrm{FeSi}_{2}$ & -5.5 & -0.11 & - \\
& $\gamma-\mathrm{FeSi}_{2}$ & -3.7 & -0.74 & - \\
$\mathrm{Co}$ & $\mathrm{CoSi}_{2}$ & 3.4 & -0.08 & - \\
$\mathrm{Ni}$ & $\mathrm{NiSi}_{2}$ & 1.2 & -0.024 & $\begin{array}{l}\text { Punched-out } \\
\text { dislocations }\end{array}$ \\
$\mathrm{Cu}$ & & & & Metastable SFs \\
& $\mathrm{Cu}_{3} \mathrm{Si}$ & 150 & 0.55 & $\begin{array}{l}\text { Frank-type SFs } \\
\text { edge dislocations }\end{array}$ \\
& & & & Edge dislocations \\
$\mathrm{Pd}$ & $\mathrm{Pd}_{2} \mathrm{Si}$ & 100 & 0.50 &
\end{tabular}

and show remarkable structural and electronic similarities [58] to the silicon lattice. The $\mathrm{CaF}_{2}$ unit cell has only a small misfit to that of silicon and contains the same number of $\mathrm{Si}$ atoms. The transition from $\mathrm{Si}$ to $M \mathrm{Si}_{2}(M=\mathrm{Fe}, \mathrm{Co}, \mathrm{Ni})$ can be imagined as a replacement reaction, by which every second $\mathrm{Si}$-atom is pushed from its lattice into the tetrahedral interstitial site and replaced by an $M$-atom. Every Siatom has four nearest neighbors, which are $M$, and every $M$-atom has eight nearest neighbors, which are $\mathrm{Si}$. Theoretical calculations for $\mathrm{Si} / \mathrm{Co}$ and $\mathrm{Si} / \mathrm{Ni}$ have demonstrated that, e.g., at the $\mathrm{NiSi}_{2}(111) / \mathrm{Si}(111)$ interface the charge densities are close to "scissor and paste" joining of the bulk densities [58]. The charge distribution in the di-silicide around $\mathrm{Si}$ is similar to that in bulk $\mathrm{Si}$, but with the $\mathrm{Si} s p^{3}$-hybrids now overlapping through a common $3 \mathrm{~d}$-atom $[59,60]$. Within the density of states, a quasi-gap separates bonding and antibonding states. For $\mathrm{CoSi}_{2}$ and $\mathrm{NiSi}_{2}$, the Fermi level is close to this quasi-gap, which has been considered as crucial in stabilizing the $\mathrm{CaF}_{2}$-structure. For $\gamma-\mathrm{FeSi}_{2}$, the Fermi level is shifted into the range of high density of d-states below the quasi-gap, which leads to a Jahn-Teller-like instability of $\gamma-\mathrm{FeSi}_{2}$ [61]. For $\beta-\mathrm{FeSi}_{2}$ [62], which can be regarded as a distorted fluorite structure [63], a crystal field splitting opens a gap at the Fermi level, so that it is one of the very few semiconducting disilicides.

\subsubsection{Metastable defect configurations}

Precipitation of dissolved impurities is driven by the gain $\Delta f_{\text {chem }}$ of chemical free-energy, frequently termed chemical driving force for precipitation [64]. For highly diluted systems like metal impurities in silicon, it can be calculated as

$\Delta f_{\text {chem }}=k_{\mathrm{B}} T \ln \frac{c}{c_{\mathrm{eq}}}$ 
where $c$ and $c_{\text {eq }}$ denote actual and equilibrium concentration of the impurity, respectively. Under the condition of normal supersaturation specified by a driving force of several $k_{\mathrm{B}} T$, precipitation is expected to proceed by nucleation and growth of the silicon-richest silicide of the respective metal-silicon phase diagram [65]. Since a solid solution of interstitially dissolved transition metal impurities in silicon easily runs into large supersaturation when cooled from high temperature, however, the free energy available for the nucleation of the silicide phase may amount then to 0.5 to $1.5 \mathrm{eV}$ per metal atom. This is due to the fact that the solubility of these transition elements is exponentially decreasing with decreasing temperature with activation enthalpies between 1.5 and about $3 \mathrm{eV}[9,66]$.

Under such conditions, metastable precipitates with nonequilibrium shape, structure, or composition might occur, which, due to their large growth rate and in spite of their larger chemical potential, win the competition with the equilibrium phase, i.e., they are selected for kinetic reasons. Indeed, when a solid solution of nickel in silicon is quenched from high temperatures to room temperature, one observes very thin and strictly planar platelets consisting of two $\mathrm{NiSi}_{2}(111)$ planes coherent to $\mathrm{Si}(111)$ bordered by a dislocation loop [7] (Fig. 8a). The latter is a geometrically necessary dislocation that results from the atomic structure of the

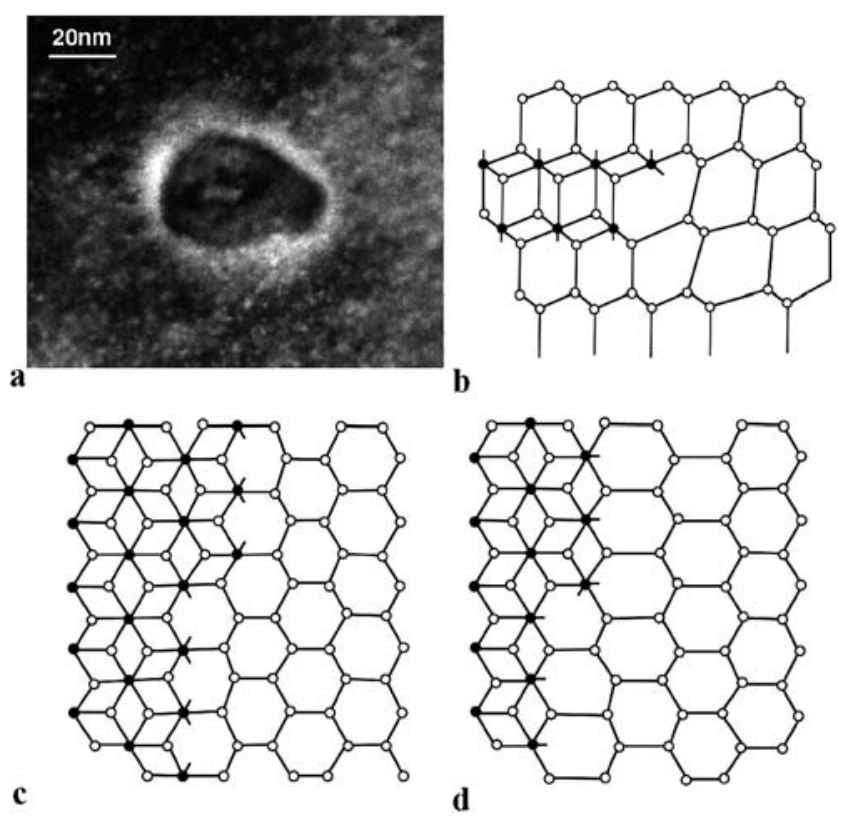

Fig. 8 Metastable plate-shaped $\mathrm{NiSi}_{2}$ precipitates. (a) Weak-beam darkfield micrograph of a platelet inclined with respect to the electron beam showing the bordering dislocation which has a Burgers vector of $b=\frac{a}{4}\langle 111\rangle$; (b) possible core structure of the dislocation in $\langle 110\rangle$ cross-section; (c) and (d) plan view of the dislocation core structure in the first (c) and second (d) $\{111\}$ layer; please note that the core structure is only slightly affected by the curvature of the dislocation (after [10]); in (b)-(d) open and closed circles refer to silicon and nickel atoms, respectively two large $\mathrm{NiSi}_{2} /(111) \mathrm{Si}$ interfaces and has a Burgers vector of $a / 4\langle 111\rangle$, which is neither possible in $\mathrm{NiSi}_{2}$ nor in silicon and can only exist as part of the precipitate/matrix interface. The formation of the bordering dislocation severely hampers the nucleation process due to its large self energy but is a prerequisite for fast particle growth. Although composed of two $\mathrm{NiSi}_{2}$ (111)-planes, the platelet is metastable with respect to its shape, since the coordination of all $\mathrm{Ni}$ atoms is seven compared to eight in the equilibrium phase. The platelets with only two $\mathrm{NiSi}_{2}(111)$ planes have been observed with diameters ranging from $7 \mathrm{~nm}$ to $900 \mathrm{~nm}$ after quenching from $750^{\circ} \mathrm{C}$ to $1050^{\circ} \mathrm{C}$ with rates of about $1000 \mathrm{~K} / \mathrm{s}$ to $2000 \mathrm{~K} / \mathrm{s}$. The perfect flatness of the platelets for this large range of diameters exhibits the dislocation core, where those two planes terminate, as the only channel by which platelets grow. Figure 8 schematically shows the possible core structure along the $\langle 110\rangle$ cross-section, Fig. $8 \mathrm{~b}$, illustrating possible sites for incorporating interstitial nickel atoms, and the $\langle 111\rangle$ plan view (Figs. $8 \mathrm{c}$ and d) indicating only slight perturbations in the dislocation core at curved segments.

A convincing proof of the conclusion that the platelets are dynamically stabilized is the first process which transforms the thin $\mathrm{NiSi}_{2}$-platelets into a more compact shape and thereby brings them closer to equilibrium is internal ripening. On annealing at temperatures between 200 and $350^{\circ} \mathrm{C}$ the platelet diameter decreases with a simultaneous increase of particle thickness leaving the total number of precipitates unchanged. Internal ripening is driven by a reduction of the platelets high-energy elements, i.e., mainly of the dislocation ring. There is good evidence from Mößbauer spectroscopy that the same plate-shaped precipitates occur for cobalt [67], including internal ripening, but on a concentration level which is about three orders of magnitude smaller compared to nickel.

The precursor stages of thin $\mathrm{NiSi}_{2}$ or $\mathrm{CoSi}_{2}$ precipitates could not be reached experimentally so far mostly because of the high mobility of interstitial cobalt and nickel in particular at lower temperatures. Diffusion of interstitial iron is significantly slower so that it can be kept in solution by rapid quenching to room temperature or as pairs with shallow acceptors. Annealing then allows pursuing the temporal evolution of iron precipitation under large driving forces. So far, no microscopic studies are available, but some proposals have been derived from EPR- and DLTS-data [68]. In a first step $(\mathrm{Fe})_{n}$-complexes with $n=2,4$ are formed followed by clusters of many $\mathrm{Fe}_{i}$-atoms around $200^{\circ} \mathrm{C}$ followed by precipitates, which have been supposed to be $\gamma$-FeSi 2 -precipitates (see Sect. 3.1.2)

The precipitation of interstitial copper is accompanied by a large volume expansion which has to be relaxed by elastic or plastic deformation, or by the emission and condensation of silicon self-interstitials. Fast quenching ( $2000 \mathrm{~K} / \mathrm{s})$ 


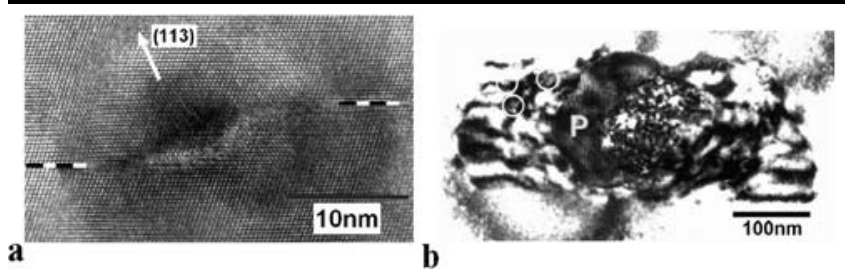

Fig. 9 Metastable copper-silicide precipitates. (a) High-resolution electron micrograph showing a plate-shaped precipitate with segments parallel to (111)-planes (indicated by dashed lines) and (113) planes; (b) bright-field micrograph of an inclined plate-shaped defect: the central copper silicide precipitate ('P') is surrounded by a stacking fault which shows horizontal fringes; white circles mark spherical $\mathrm{Cu}_{3} \mathrm{Si}$ precipitates. Such configurations can be viewed as a particle colony in statu nascendi

from high temperature produces plate-shaped precipitates of irregular shape with habit plane segments that are partly parallel to $\mathrm{Si}(111)$ - and partly parallel to $\mathrm{Si}(113)$-planes (Fig. 9a). Lowering the quenching rate to about $1000 \mathrm{~K} / \mathrm{s}$ results in copper silicide platelets on $\mathrm{Si}(111)$ surrounded by an extrinsic stacking fault, apparently generated by condensation of silicon interstitials [69-71]. Figure $9 \mathrm{~b}$ is a bright-field TEM image showing a central platelet $(\mathrm{P})$ and stacking fault fringes. In addition, small spherical precipitates (marked by circles in Fig. 9b) have formed, which fact provides evidence that such configurations can be viewed as the initial state of copper silicide particle colonies that are typical for late stages of copper precipitation realized by slow cooling [72] or Ostwald ripening [71]. It should be noted that the central platelets have been observed to transform into spherical precipitates once misfit relaxation is due to selfinterstitial condensation into stacking faults or dislocation loops. This can be taken as evidence that misfit partly relaxes by elastic deformation prior to the nucleation of sinks for self-interstitials.

The condensation of self-interstitials emitted from growing $\mathrm{Cu}_{3} \mathrm{Si}$ precipitates is a premise for fast relaxation of copper interstitial supersaturation and may be regarded as the bottleneck of homogeneous precipitation: assuming that the misfit is exclusively accommodated by silicon selfinterstitials emitted from growing $\mathrm{Cu}_{3} \mathrm{Si}$ precipitates the resulting supersaturation of self-interstitials counterbalances the chemical driving force for copper precipitation and virtually prevents copper precipitation unless they also can precipitate at some sinks. This point will be referred to again in Sects. 3.2 and 3.3.

\subsubsection{Deep band-like states at silicide precipitates}

Electronically, silicide precipitates are small systems that may have a quasi-continuous spectrum of electronic states in the band gap of silicon, represented by a density of states $N_{\mathrm{p}}(E)$ and by capture cross sections of these states for electrons $\sigma_{\mathrm{e}}(E)$ and for holes $\sigma_{\mathrm{h}}(E)$. From the different tech- niques that probe the emission and capture of charge carriers at defects and thereby open an access to the properties of $N_{\mathrm{p}}(E)$, mainly DLTS and minority carrier transient spectroscopy, MCTS [73] have been applied to study platelets and electron-beam induced current, EBIC, to study larger precipitates. An exemplary compilation of DLTS data is provided in Fig. 10, where the pulse-length dependence of the respective DLTS lines for nickel- (Fig. 10a), copper(Fig. 10b), and iron-related extended defects (Figs. 10c and d) are shown. The signals in (a), (b), and (d) show the typical behavior of deep band-like states, i.e., the common high-temperature signal for different pulse-lengths, whereas the spectra in (c) follow a pronounced logarithmic capture and can be normalized, both features proving the localized nature of the extended defects states [37].

To establish the connection between $N_{\mathrm{p}}(E)$ and the structure of the precipitates, HREM studies briefly reviewed in the previous section have been used to identify the structural units of the precipitates which could be electrically active. For thin $\mathrm{NiSi}_{2}$-platelets, the possible electronic states are associated with the dislocation bordering the platelets or the platelet/(111)Si interfaces, both consisting of Ni-atoms with deficient coordination (see Figs. 8b-d). For one-dimensional (1D) defects, like, e.g., the dislocation bounding the $\mathrm{NiSi}_{2}$ platelets, the density of states is given by

$N_{\mathrm{p}}(E)=\frac{N_{\mathrm{d}}}{\pi \sqrt{\left(E-E_{\mathrm{p}}+\Delta E\right)\left(E_{\mathrm{p}}-E\right)}}$,

where $N_{\mathrm{d}}$ denotes the total density of active core states, and $E_{\mathrm{p}}$ and $\Delta E$ are the upper edge of the deep energy band and its width, respectively. For two-dimensional defects, like precipitate/matrix interfaces

$N_{\mathrm{p}}(E)= \begin{cases}\frac{N_{\mathrm{i}}}{\Delta E}, & E_{\mathrm{p}}-\Delta E \leq E \leq E_{\mathrm{p}}, \\ 0, & \text { else, }\end{cases}$

with $N_{\mathrm{i}}$ being the total density of electrically active interface states. The parameters describing the density-of-states can be determined by numerically fitting DLTS lines measured for different pulse lengths and rate windows. In addition to position and width of the deep bands, the dependence of the capture barrier on the total occupation $F$ is assumed as $e \Phi=\alpha\left(F-F^{(N)}\right)$, where $\alpha$ and $F^{(N)}$ are to be determined from the fit. The latter denotes the fraction of the defect states occupied by electrons when the defect is electrically neutral. For fitting to DLTS-data, $\sigma_{\mathrm{e}}$ and $\sigma_{\mathrm{h}}$ were taken as independent of $E$.

A unique core structure with features of a one-dimensional system has been proposed for dislocations bordering thin, strictly planar $\mathrm{NiSi}_{2}$-platelets. They are free of jogs and kinks, and the core defects, necessary to generate their curvature, are weak perturbations with six- and five-fold coordi- 
Fig. 10 DLTS lines obtained from extended defects related to nickel, copper, and iron. (a) Plate-shaped $\mathrm{NiSi}_{2}$ precipitates after rapid quenching from high temperature [10], (b) copper silicide platelets after rapid quenching from $850^{\circ} \mathrm{C}[8,68$, 71, 74]; (c) localized states tentatively attributed to $\mathrm{Fe}_{i}$ clusters after iron in-diffusion at $1200^{\circ} \mathrm{C}$ followed by quenching and additional annealing at $200^{\circ} \mathrm{C}$ [75]; (d) band-like states observed after iron in-diffusion at $1200^{\circ} \mathrm{C}$, quenching and subsequent annealing at $250^{\circ} \mathrm{C}$, which has been associated with iron silicide precipitates [76] with a point defect signal overlapping at about $120 \mathrm{~K}$. For details, refer to the given references, please

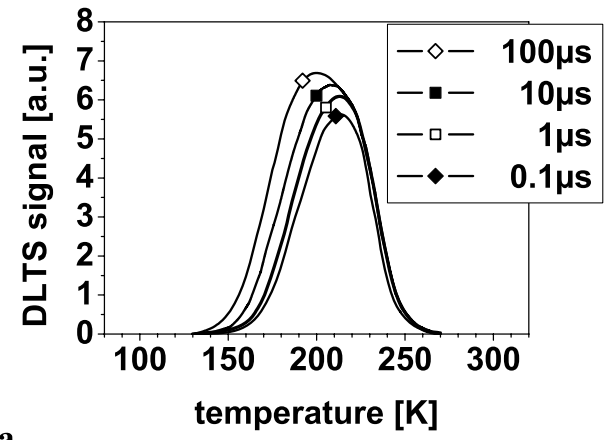

a

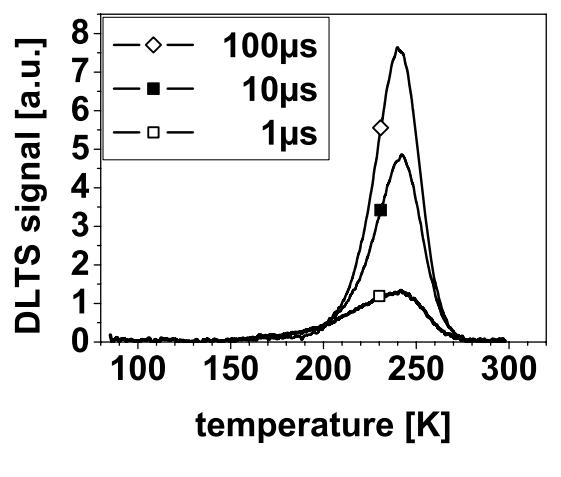

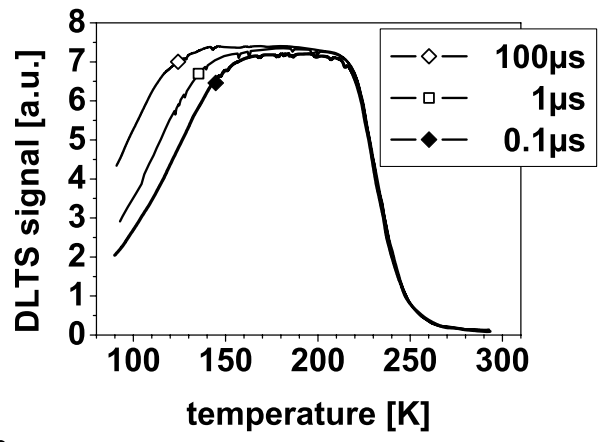

b

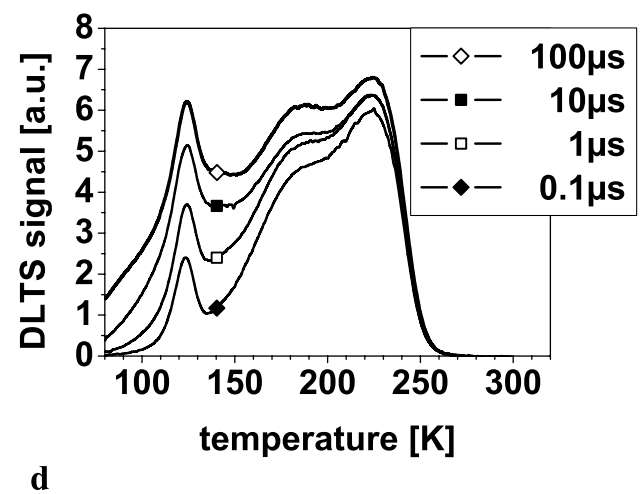

nated Ni-atoms instead of four- and six-fold for their straight segments (see Figs. 8b-d).

Indeed, a broadened DLTS-line in n-type silicon (Fig. 10a) exhibiting the characteristics of a band-like $N_{\mathrm{p}}(E)$ was assigned to the dislocation loops bordering thin $\mathrm{NiSi}_{2}$-platelets [10]. Experimentally, this assignment has been justified by the change of $N_{\mathrm{p}}(E)$ from band-like to localized states during internal ripening occurring on annealing between 200 and $350^{\circ} \mathrm{C}$ as soon as small islands form at the rim of the platelets. Recent theoretical investigations using density functional methods have confirmed this interpretation [77]. They have found $N_{\mathrm{p}}(E)$ to be caused by d-electrons at the $3 \mathrm{~d}$-atom and, to a lesser extent, by p-character states on the Si-atoms directly bonded to them. The 3d-atoms at the dislocation contribute much stronger to $N_{\mathrm{p}}(E)$ than the interfacial $3 \mathrm{~d}$-atoms. Numerical fits of the model described by (4) to the total set of DLTS-lines, obtained for thin $\mathrm{NiSi}_{2}$-platelets in n-type silicon (nickel in-diffusion at $900^{\circ} \mathrm{C}, 2000 \mathrm{~K} / \mathrm{s}$, average platelet diameter: $37 \pm 6 \mathrm{~nm}$ ) have yielded the parameters summarized in Table 1 [78]. Although the fit for $\mathrm{NiSi}_{2}$ platelets is excellent (see Fig. 4 in [78]), the obtained parameters have to be considered as preliminary for the following reasons:

- One additional parameter, used for the fit and not shown in the table, is an effective point charge $q^{*}$, which approximately describes the effect of the dislocation strain field in electron and hole emission [79]. The value of $q^{*}=2.7$ obtained from the fit is at least twice as large as estimated values $(0.7-1.5)$.

- To treat the effect of the external electric field on $N_{\mathrm{p}}(E)$, the rigid band shift for a mean value of the field over the platelet has been used. The neglect of the field variation along the platelet is expected to be responsible for the too small value of $N_{\text {tot }}$.

- The existence of the interfacial band-like states and their coupling to the dislocation states have not been taken into account so far.

Recent DLTS-studies of thin $\mathrm{NiSi}_{2}$-platelets in p-type silicon have revealed the contribution of interfacial states to $N_{\mathrm{p}}(E)$ [80]. The band-like part of $N_{\mathrm{p}}(E)$ of the interface remains band-like during internal ripening of the platelets $\left(310^{\circ} \mathrm{C}, 60 \mathrm{~min}\right)$. Although the two components of $N_{\mathrm{p}}(E)$ originate from a 1-D and 2-D structural unit of the platelet, they are coupled by a common long-range electrostatic and elastic field and most probably by an exchange rate between the two structural units. For an extension of the defect electronic model to this situation, only qualitative proposals have been made so far.

Although the first precipitates of $\mathrm{Cu}$ in silicon, as obtained by quenching from $850^{\circ} \mathrm{C}$ with a rate of $2000 \mathrm{~K} / \mathrm{s}$, are platelets, their shape and later stages are strongly affected by the large volume expansion associated with $\mathrm{Cu}_{3} \mathrm{Si}$ formation in silicon [81]. The strict alignment of $\mathrm{Si}(111)$, observed for the $\mathrm{NiSi}_{2} / \mathrm{Si}$ interface is lost for the $\mathrm{Cu}_{3} \mathrm{Si} / \mathrm{Si}$ interface, yet a preference to this alignment remains, es- 
Table 2 Results of a numerical fit of the model to experimental data obtained for $\mathrm{NiSi}_{2}$-platelets in n-type silicon after nickel indiffusion at $900^{\circ} \mathrm{C}$, followed by quenching with an estimated rate of $2000 \mathrm{~K} / \mathrm{s}$ which results in an average platelet diameter of $37 \pm 6 \mathrm{~nm}$ according to TEM. For copper-related data, parameters of numerical simulations reproducing qualitatively the DLTS-characteristics and the unusual line shape are quoted

\begin{tabular}{|c|c|c|c|c|c|c|c|c|}
\hline & $N_{\mathrm{d}}(E)$ & $\begin{array}{l}E_{\mathrm{C}}-E_{\mathrm{p}} \\
{[\mathrm{eV}]}\end{array}$ & $\begin{array}{l}\Delta E \\
{[\mathrm{eV}]}\end{array}$ & $\begin{array}{l}\alpha \\
{[\mathrm{eV}]}\end{array}$ & $F^{(N)}$ & $\begin{array}{l}\sigma_{\mathrm{e}} \\
{\left[10^{-16} \mathrm{~cm}^{2}\right]}\end{array}$ & $\begin{array}{l}\sigma_{\mathrm{h}} \\
{\left[10^{-16} \mathrm{~cm}^{2}\right]}\end{array}$ & $\begin{array}{l}N_{\text {tot }} \\
{\left[\mathrm{cm}^{-3}\right]}\end{array}$ \\
\hline $\mathrm{Ni}$ & Equation (4) & 0.42 & 0.29 & 0.7 & 0.33 & 500 & 50 & $2 \times 10^{14}$ \\
\hline $\mathrm{Cu}$ & Equation (5) & 0.15 & 0.29 & 0.6 & $\geq 0.7$ & 3 & - & $1.8 \times 10^{14}$ \\
\hline
\end{tabular}

pecially for platelets showing strain relief by an extrinsic stacking fault surrounding them. Internal ripening $\left(260^{\circ} \mathrm{C}\right.$, $30 \mathrm{~s}$ ) transforms the plate-like into spherical precipitates and leaves the band-like character of the DLTS-line unchanged. It is the reason why the DLTS-line has been assigned to the precipitate/Si interface.

The DLTS-line of the first platelet $\left(850^{\circ} \mathrm{C}, 2000 \mathrm{~K} / \mathrm{s}\right)$ is of trapezoidal form with a width of about $100 \mathrm{~K}$ (compare Fig. 9b) [74, 81]. This quite unusually shaped line and all its variations with frequency and filling pulse width have been reproduced by numerical simulation using a $2 \mathrm{D}$ $N_{\mathrm{p}}(E)$. With increasing platelet diameters, the DLTS-line shapes round off and the line width decreases. It is not clear so far what changes of the platelet electronic structure are responsible for these effects. For $\mathrm{Cu}_{3} \mathrm{Si}$ precipitates, also the effect of platelet thickness on the DLTS-line shape has been studied [81]. For platelets with diameter of $240 \mathrm{~nm}$ and thickness of $5 \mathrm{~nm}$ (copper in-diffusion at $850^{\circ} \mathrm{C}$ followed by quenching with $200 \mathrm{~K} / \mathrm{s}$ ) the DLTS-line is only slightly broader than that of a point defect. Application of the defect electronic model would lead to a narrow set of localized states still behaving as an extended defect which can be inferred from the logarithmic capture kinetics.

Table 2 summarizes the density-of-states and the parameters used to fit DLTS lines associated with $\mathrm{NiSi}_{2}$ platelets and to simulate the spectra observed for copper silicide precipitates. Comparing the parameters obtained for $\mathrm{Cu}_{3} \mathrm{Si}$ platelets with those for $\mathrm{NiSi}_{2}$-platelets one notes that

- The bandwidth $\Delta E$ of $N_{\mathrm{p}}(E)$ is about the same.

- The occupation of the neutral platelet $F^{(N)}$ is significantly larger for $\mathrm{Cu}_{3} \mathrm{Si}$ than for $\mathrm{NiSi}_{2}$, which results in the trapezoidal shape of the DLTS signal related to $\mathrm{Cu}_{3} \mathrm{Si}$ precipitates.

- The band center is less deep for copper-related defects, so that hole emission is significant for $\mathrm{NiSi}_{2}$, but not for $\mathrm{Cu}_{3}$ Si-platelets.

It should be mentioned here that, according to these results, copper silicide precipitates are positively charged under most conditions, which has been related to the reduced precipitation rate of copper in p-type silicon [82].

Iron clustering and precipitation can be investigated during annealing a supersaturated solid solution, since $\mathrm{Fe}_{i}$ can be kept in solution by rapid quenching from diffusion temperature. By means of EPR it has been shown that $\mathrm{Fe}_{i}$ in $\mathrm{p}$ and n-type silicon starts to disappear from solution by forming small clusters $(\mathrm{Fe})_{n}$ with $n=2$ and $n=4$. The structure of the clusters has not been settled unambiguously, one of the possible configurations starts from clusters with $\mathrm{Fe}$ on interstitial positions for $n=2$ and $n=4$.

(Fe)2-pairs are found directly after quenching from $1200^{\circ} \mathrm{C}$ but disappear just above room temperature [83]. On isochronal annealing for $60 \mathrm{~min}$, the formation of $(\mathrm{Fe})_{4}$-clusters starts at $120^{\circ} \mathrm{C}$ and has been found to be related to the set-in of the $\mathrm{Fe}_{i}$-concentration $\left[\mathrm{Fe}_{i}\right]$ drop [84]. Within the decline of $\left[\mathrm{Fe}_{i}\right]$, the concentration of $(\mathrm{Fe})_{4}$, $\left[(\mathrm{Fe})_{4}\right]$ runs through a maximum around $140^{\circ} \mathrm{C}$ and reaches a plateau when $\left[\mathrm{Fe}_{i}\right]$ has dropped below $1 \%$ of its initial value $\left(160^{\circ} \mathrm{C}\right)$. The maximum of $\left[(\mathrm{Fe})_{4}\right]$ indicates a competition between $(\mathrm{Fe})_{4}$-generation and $(\mathrm{Fe})_{4}$-growth to larger clusters or silicide precipitates by $\mathrm{Fe}_{i}$-incorporation. The remaining $(\mathrm{Fe})_{4}$-clusters survive to higher temperatures $\left(250^{\circ} \mathrm{C}\right)$, then first dissociate to form larger clusters or precipitates.

Large Fe-clusters and iron silicide precipitates have not been detected by EPR so far but have been studied by DLTS in p-type silicon [75]. In these experiments the indiffusion was carried out at temperatures between $950^{\circ} \mathrm{C}$ $\left(\left[\mathrm{Fe}_{i}\right]=1.4 \times 10^{14} \mathrm{~cm}^{-3}\right)$ and $1200^{\circ} \mathrm{C}\left(\left[\mathrm{Fe}_{i}\right]=1.6 \times\right.$ $10^{16} \mathrm{~cm}^{-3}$ ) and finished by rapid quenching followed by annealing at $200^{\circ} \mathrm{C}$ or $250^{\circ} \mathrm{C}$. Starting with an iron concentration $[\mathrm{Fe}] \simeq 1.6 \times 10^{16} \mathrm{~cm}^{-3}$ as has been used for the EPR studies all annealing steps yielded Fe-precipitates, while for the smallest initial [Fe]-values of $1.4 \times 10^{14} \mathrm{~cm}^{-3}$, annealing at $200^{\circ} \mathrm{C}$ for $30 \mathrm{~min}$ only changed the ratio of interstitial iron and iron-boron pair concentrations. Annealing at $250^{\circ} \mathrm{C}$ for only $15 \mathrm{~min}$, however, yielded $\mathrm{Fe}_{i}$-clusters. The latter represent themselves in DLTS with an emission characteristic which is very similar to that of $\mathrm{Fe}_{i}$ but with a capture characteristics completely different (see Fig. 10c). It follows from the logarithmic capture law which means that hole capture is strongly impeded by an occupation-dependent barrier. Furthermore, the lines coincide after normalization, a fingerprint of deep localized states at extended defects [37]. Generally, extended defects are associated with broadened 
DLTS-line due to the fact that their density of states $N_{\mathrm{p}}(E)$ spreads over a finite energy range in the silicon band gap [3]. The unusual feature that the DLTS-line assigned to the Fecluster is almost not broadened and yields about the same emission characteristics as $\mathrm{Fe}_{i}$ has been taken as evidence that the iron atoms in the cluster occupy the interstitial $T_{\mathrm{d}}$-site like isolated $\mathrm{Fe}_{i}$ and also have the same nearest neighbor environment. Since the lattice of interstitial

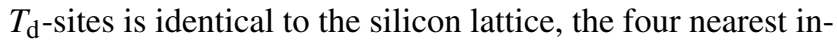
terstitial $T_{\mathrm{d}}$-sites of $\mathrm{Fe}_{i}$ in the cluster must be empty. These are the four sites inside the silicon unit cell when $\mathrm{Fe}_{i}$ occupies the cell centre. The next nearest interstitial $T_{\mathrm{d}}$-sites belonging (with a fraction of 1/4) to the silicon unit cell are in the middle of its edges. If these were occupied by $\mathrm{Fe}_{i}$, the cluster would consist of a phase with occupied and unoccupied $T_{\mathrm{d}}$-sites in equal parts.

Although the driving force of the supersaturated solid solution of $\mathrm{Fe}$ in $\mathrm{Si}$ is lowered by the $\mathrm{Fe}_{i}$-cluster formation, these clusters are metastable and, under conditions allowing further relaxation, should be replaced by $\mathrm{FeSi}_{2}-$ precipitates. Indeed, after annealing a solid solution with $[\mathrm{Fe}] \simeq 1.6 \times 10^{16} \mathrm{~cm}^{-3}$ at $200^{\circ} \mathrm{C}$ or $250^{\circ} \mathrm{C}$ for $15 \mathrm{~min}$ a different and new DLTS-spectrum appears (Fig. 10d) [76]. It has been decomposed into a point defect line and a significantly broadened line, which resembles by its hump-like shape, its variation with filling pulse length and with correlation frequency to the feature measured for $\mathrm{NiSi}_{2}-$ and $\mathrm{Cu}_{3} \mathrm{Si}$ precipitates. Therefore, it has been tentatively associated to $\mathrm{FeSi}_{2}$-precipitates that have a band-like $N_{\mathrm{p}}(E)$ spread over some tenth $\mathrm{eV}$ located in the lower half of the silicon band gap.

Possible candidates for the related $\mathrm{FeSi}_{2}$-phase are $\beta$-FeSi 2 , the thermodynamically stable phase below $915^{\circ} \mathrm{C}$, and $\gamma-\mathrm{FeSi}_{2}$ which is a metastable disilicide isomorphous to $\mathrm{CoSi}_{2}$ and $\mathrm{NiSi}_{2}$. It has been observed as a precursor phase of epitaxial growth of $\beta$-FeSi 2 on $\mathrm{Si}(111)$ under several nonequilibrium conditions like crystallization from vapor phase $[85,86]$, from the liquid phase after pulse laser irradiation [87] or induced by ion beam implantation $[88,89]$. If the DLTS lines (Fig. 10d) were tentatively attributed to $\gamma-\mathrm{FeSi}_{2}$ precipitates, their possible precursor phase could be the $\mathrm{Fe}_{i}$-clusters with equal parts of occupied and unoccupied $T_{\mathrm{d}}$-sites, as mentioned above. A simple replacement reaction, by which a $\mathrm{Fe}_{i}$-atom pushes a $\mathrm{Si}$-atom onto a $T_{\mathrm{d}}$-site transforms such a cluster into $\gamma-\mathrm{FeSi}_{2}$. This hypothetical scenario has the intriguing charm of its natural extension to $\mathrm{CoSi}_{2}$ and $\mathrm{NiSi}_{2}$ precipitate nucleation, a microscopic proof is still lacking, however.

\subsection{Large precipitates}

Metal silicide precipitates beyond those early stages discussed in the previous section are characterized by approaching equilibrium configurations. Experimentally, they can be formed by slow cooling of defect-free silicon where predominant precipitation occurs at wafer surfaces [90] or by additional annealing at medium temperature where precipitate coarsening (Ostwald ripening) is the dominant process. For $\mathrm{NiSi}_{2}$ precipitates, the route to equilibrium first includes a considerable thickness increase of platelets that have been observed in two different orientations with respect to the silicon, i.e., the same orientation as the silicon (type-A) and a twin orientation (type-B) with respect to silicon where the platelet habit plane serves as the twinning plane. In still later stages of particle ripening, type-A precipitates of nearly tetrahedral or octahedral shape have been observed proving the tendency of the system to reduce the total interface energy. In addition, the different thermal expansion coefficients of $\mathrm{NiSi}_{2}$ and silicon frequently lead to dislocation punching for large silicide precipitates.

Iron silicide precipitates have been experimentally observed as rod-like $\alpha-\mathrm{FeSi}_{2}$ precipitates [91] indicating their formation at high temperature during cooling, or as spheroidal $\beta$-FeSi 2 precipitates at $\mathrm{Si} / \mathrm{SiO}_{2}$-interfaces $[92,93]$ or in the bulk [94].

Copper-related precipitates evolve into the well-known particle colonies consisting of planar arrangement of nearly spherical $\mathrm{Cu}_{3} \mathrm{Si}$ precipitates (typical diameter 5-10 $\mathrm{nm}$ ) bordered by an edge dislocation loop [72]. These colonies have sizes from about $100 \mathrm{~nm}$ [71] up to almost macroscopic dimensions of a few tens of microns [72, 90] (see also Sect. 3.4). They form as the result of an autocatalytic process [72, 95-97] involving (i) $\mathrm{Cu}_{3} \mathrm{Si}$ particle nucleation on the edge dislocation loop, (ii) particle growth and condensation of emitted silicon self-interstitials at the dislocation loop which causes the latter to grow. The final process is (iii) the detaching of the dislocation loop from the precipitates restoring the initial situation.

With increasing platelet thickness a metallic $\mathrm{NiSi}_{2}$-bulk becomes coupled to interface and dislocation that establish the connection to the silicon lattice, and gradually overrides their electronic effects. The precipitate develops a metallike density of states, a Fermi energy and a work function, whose values converge (for $d>10 \mathrm{~nm}$, rapidly) towards those of the silicide phase and by which the precipitate forms a rectifying contact with the silicon matrix. For an approximate treatment, the Schottky-Mott theory of metal-semiconductor contacts has been applied to precipitate-silicon system taking the thermo-ionic emission mechanism to describe carrier recombination rate at the precipitate [11, 98]. Experimentally, these larger precipitates can be studied with respect to their individual recombination strength, using EBIC [6, 99, 100]. They generally produce extremely large EBIC contrasts on the order of 30$50 \%$, which proves efficient carrier recombination at silicide precipitates. Such investigations for $\mathrm{NiSi}_{2}$-precipitates have shown that the minority carrier diffusion length $L_{\mathrm{D}}$ 
is approximately proportional to the average distance $\delta$ between precipitates $\left(L_{\mathrm{D}} \simeq 0.7 N_{v}^{-1 / 3}, N_{v}\right.$ density of precipitates) [6]. For $\mathrm{Cu}_{3} \mathrm{Si}$-platelets, it has been shown that the ratio $L_{\mathrm{D}} / \delta$ is decreasing from 3.6 to 1.5 with $\delta$ varying from $0.6 \mu \mathrm{m}$ to $9 \mu \mathrm{m}$ [68].

\subsection{Silicide precipitation at dislocations}

The precipitation of fast diffusing transition metal impurities is strongly affected by the presence of dislocations which in general serve as heterogeneous nucleation sites [5]. In particular, metastable nonequilibrium configurations such as discussed in Sect. 3.1.1 have never been observed in the presence of dislocations indicating that kinetic limitations of silicide precipitation are effectively eliminated by dislocations [101] or quickly evolve into energetically more favorable structures in the course of precipitation.

The most obvious role of dislocations is the provision of a strain field which assists to relax the misfit and of an effective sink for intrinsic point defects produced by growing precipitates. As has been discussed above, dislocations are an integral part of copper particle colony growth, and metastable defects related to early stages of copper precipitation are obsolete if pre-existing dislocations are present. In fact, the strong tendency of copper silicide precipitates to decorate dislocations in silicon is well known since the 1950s and has been beautifully exploited to image dislocation arrangements in silicon [102].

The role of dislocations in nickel silicide precipitate formation is less obvious since the volume misfit is small (see Table 1). In this case, fast incorporation of interstitial nickel atoms into the $\mathrm{NiSi}_{2}$ particles via the core of the $b=a / 4\langle 111\rangle$ dislocations bordering the platelets has been identified as a prerequisite for fast precipitation. It has been inferred that pre-existing silicon dislocations might either assist the nucleation of this bordering dislocation or directly serve as transformation channels for nickel atoms from interstitial sites in the silicon to substitutional sites in the $\mathrm{NiSi}_{2}$ [101]. A convincing demonstration of the role of dislocations for $\mathrm{NiSi}_{2}$-precipitate formation has been given by studies of heterogeneous precipitation in $\mathrm{Cz}-\mathrm{Si}$ containing stacking faults and $\mathrm{SiO}_{2}$-particles with volume densities of $4 \times 10^{10} \mathrm{~cm}^{-3}$ and $3 \times 10^{12} \mathrm{~cm}^{-3}$, respectively $[103,104]$. After quenching (rate $2000 \mathrm{~K} / \mathrm{s}$ ) from high temperature $\left(1050^{\circ} \mathrm{C}\right)$ large $\mathrm{NiSi}_{2}$-platelets with average diameter of $220 \mathrm{~nm}$ and thickness of $25 \mathrm{~nm}$ have been observed at Frank partial dislocations surrounding the stacking fault, but none at the $\mathrm{SiO}_{2}$-precipitates.

For glide dislocations in plastically deformed silicon, a strong interaction with polyhedral type- $\mathrm{A} \mathrm{NiSi}_{2}$ precipitates has been observed by TEM $[5,105]$, which shows that dislocations not only serve as nucleation sites but also actively take part in the precipitate growth.

\subsection{Co-precipitation of metal impurities}

In the preceding part of this section transition metal precipitation has been discussed for the ideal situation of a single metal impurity. The practical situation for multicrystalline materials for photovoltaic applications, however, is the simultaneous presence of different impurities [106] which may interact during precipitation. From the point of view of thermodynamics, ternary systems containing silicon and the two metals cobalt and nickel should form disilicide precipitates of composition $\mathrm{Co}_{1-x} \mathrm{Ni}_{x} \mathrm{Si}_{2}$, where $0 \leq x \leq 1$, since these metals form ideal solutions on the metal sublattice of the disilicides [107]. For the simultaneous presence of iron and nickel (or cobalt), a more complicated behavior is expected since $\mathrm{FeSi}_{2}$ exists in several modifications (see Sect. 3.1). If one of the two metal species is copper, however, equilibrium is established between $A \mathrm{Si}_{2}$ containing a certain amount of copper, and $\mathrm{Cu}_{3} \mathrm{Si}$ containing the respective metal $A$ [108]. In all cases, no ternary intermetallic compounds are expected.

For small precipitates in the silicon matrix, interfacial energies and-especially if copper is involved-strain energy might considerably query these conclusions from bulk thermodynamics since phase equilibria may change and certain ternary silicide phases may be stabilized. Several experimental studies mainly using synchrotron-based X-ray fluorescence and X-ray absorption spectroscopy have been performed recently in order to gain chemical information about precipitate phases forming under such conditions [109]. Besides co-localized single-metal silicide precipitates complex multimetal silicide precipitates [110-112] containing iron, nickel, copper, and silicon have been reported and structurally related to the fluorite structure, i.e., they are isomorphous to $\mathrm{CoSi}_{2}, \mathrm{NiSi}_{2}$, and $\gamma-\mathrm{FeSi}_{2}$ phases. It has been inferred from such observations that multimetal silicide precipitates of homogeneous composition form at high temperature, which then may decompose during further cooling to room temperature. A special process has been proposed for conditions of slow cooling from (very) high temperature where the formation of liquid metal-silicon droplets within the silicon has been concluded from synchrotronbased X-ray microprobe investigations [109]. Such droplets will solidify and possibly chemically decompose during further cooling.

If two fast diffusing metal impurities are simultaneously present in silicon, the final state to which precipitation proceeds is, as deduced from bulk thermodynamics, the coexistence of three phases. For nickel and copper, these are: a solid solution of copper and nickel in silicon, a nickelrich silicide of $\mathrm{CaF}_{2}$-structure (denoted as $\alpha-\mathrm{NiSi}_{2}$ ) containing a certain concentration of copper, and a copper-rich $\mathrm{Cu}_{3}$ Si-like phase containing some nickel. The resulting microstructure, however, will depend on relative concentrations of metal impurities initially dissolved in the silicon. 
Fig. 11 Co-precipitation of copper and nickel in silicon. (a) TEM micrograph of precipitates inside a large particle colony; the small precipitate shows Moire fringes typical for $\mathrm{Cu}_{3} \mathrm{Si}$ precipitates, whereas the big particle consists of a nickel-rich and a copper-rich region (b) results of EDX analysis at positions indicated by black discs in (a); the composition of the nickel-rich region is close to $\mathrm{NiSi}_{2}$, whereas a small amount of nickel is present in the copper-rich part; (c) LBIC micrograph of a precipitate colony after copper diffusion showing contrasts of up to $50 \%$; (d) LBIC micrograph of a precipitate colony after copper-nickel co-diffusion; the contrasts are typically $50 \%$
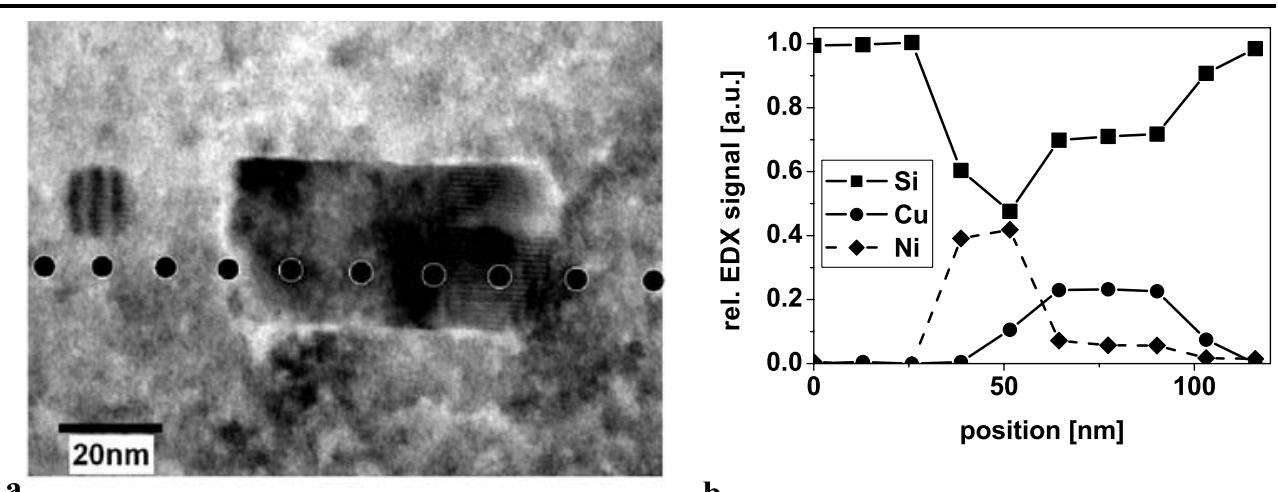

b

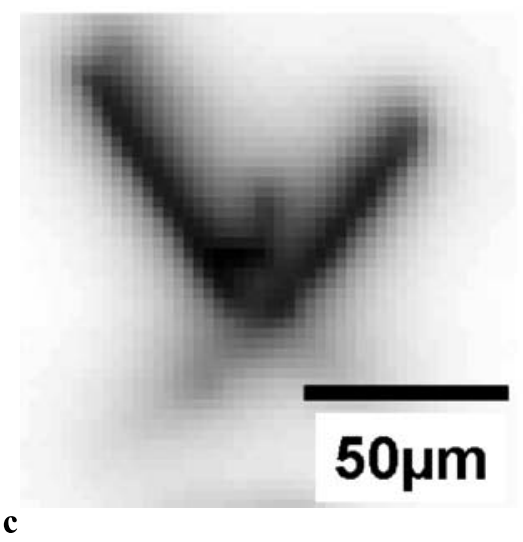

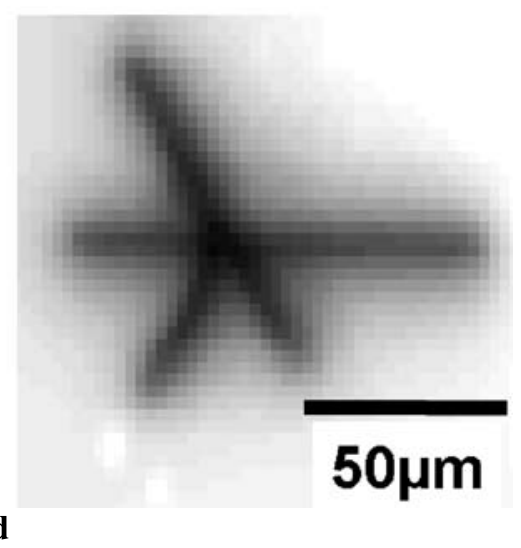

This has recently been demonstrated by a series of experiments on co-precipitation of nickel and copper in silicon under copper-rich conditions and nickel-rich conditions [113].

For copper-rich conditions, large particle colonies are observed by TEM virtually identical to those well known for copper precipitation. Chemical and structural analyses reveal that the small particles are close to $\mathrm{Cu}_{3} \mathrm{Si}$ in composition containing a few percent nickel (the nickel-to-copper ratio in the precipitates is about 1 to 20); an example of such a small precipitate is shown in Fig. 11a. In addition, a small density of nickel-rich precipitates can be found inside the colonies (large particle in Fig. 11a), which is $\alpha-\mathrm{NiSi}_{2}$, as is consistently deduced from high-resolution imaging and chemical analysis using energy-dispersive X-ray spectroscopy, EDX, in the TEM (see Fig. 11b). A typical situation is furthermore indicated by Figs. 11a and b, i.e., a copper-rich precipitate directly attached to the $\mathrm{NiSi}_{2}$ particle. It is noteworthy that the nickel-rich precipitates seem to be regularly distributed inside such colonies indicating their nucleation at the bordering edge-dislocation loop during colony growth (compare Sect. 3.2 for the growth mode of the colonies). A scenario compatible with these observations includes the following - not necessarily sequentialprocesses: (i) formation of copper silicide colonies, (ii) segregation of nickel into the $\mathrm{Cu}_{3} \mathrm{Si}$ precipitates up to a max- imum nickel-to-copper ratio of about $5 \%$, (iii) relaxation of the remaining nickel supersaturation by the formation of $\alpha-\mathrm{NiSi}_{2}$ precipitates containing copper. These observations are in accord with thermodynamics outlined above.

Under nickel-rich conditions plate-shaped precipitates parallel to $\mathrm{Si}(111)$ planes are observed by TEM (Fig. 12). Figure $12 \mathrm{a}$ is a bright-field electron micrograph of a platelet with a diameter of $1.5 \mu \mathrm{m}$ and a thickness of $35 \mathrm{~nm}$ which has punched out dislocations in particular at the top end of the precipitate. Closer inspection shows that the interior of the platelet is a two-phase region as can be deduced from Fig. 12b. Chemical analysis of the central part showing horizontal fringes (marked "N") gives a composition close to $\mathrm{Si}_{0.63} \mathrm{Ni}_{0.3} \mathrm{Cu}_{0.07}$, whereas the smaller particles exhibiting almost vertical Moiré fringes are copper-rich; the exact composition cannot be determined due to the overlapping nickel-rich precipitate along the electron beam. Figure $12 \mathrm{c}$ shows that small precipitates have also formed at the dislocations punched out from the edge of the nickel-rich silicide platelet; the Moiré contrast and chemical analysis provides evidence of $\mathrm{Cu}_{3} \mathrm{Si}$ precipitates with a nickel content below the detection limit of EDX. The scenario which can be deduced from these observations includes several processes that are operative during cooling from high temperature: (i) formation of nickel-rich platelets with composition close 


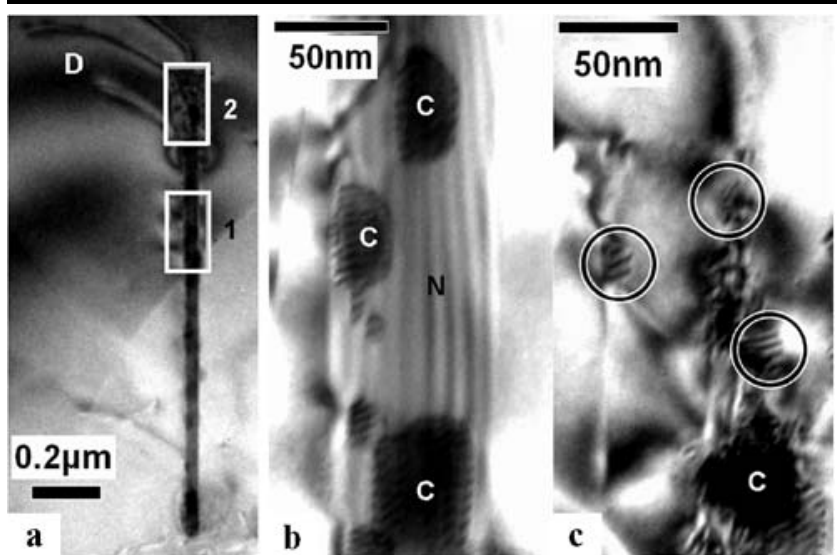

Fig. 12 Co-precipitation of nickel and copper in silicon under nickel-rich conditions. (a) TEM micrograph showing a plate-shaped precipitate viewed edge-on with punched-out dislocations (D) in the upper part of the image; rectangles " 1 " and " 2 " indicate areas shown in detail in (b) and (c), respectively; (b) bright-field image of a nickel-rich precipitate ("N") with internal copper-rich particles ("C"); (c) copper-rich precipitates (marked by circles or "C") attached to punched-out dislocations in the silicon matrix

to $\mathrm{NiSi}_{2}$, (ii) segregation of copper into the platelet up to an atomic fraction of $13 \%$ estimated from the total copper content of the platelet, (iii) decomposition of the ternary precipitate phase during cooling, and (iv) $\mathrm{Cu}_{3} \mathrm{Si}$ precipitation at punched-out dislocations probably during late stages of precipitation which relaxes the remaining supersaturation of interstitial copper in the silicon.

To conclude this section it should be mentioned that the recombination activity of defects formed by co-precipitation of copper and nickel are virtually identical to those of single-metal precipitates. Light-beam-induced current measurements of copper-silicide colonies (Fig. 11c) and coppernickel-silicide colonies (Fig. 11d) show comparable contrasts of about 50\% [114]. Such values have previously been also reported for EBIC investigations of copper-silicide particle colonies [99] and $\mathrm{NiSi}_{2}$ platelets [6].

\section{Summary and conclusion}

Electronic properties of dislocations and metal silicide precipitates in silicon have been described and related to their atomic structure where possible. The apparently distinct topics are closely linked due to the strong interaction of dislocations with transition metal impurities. The important role of dislocations as heterogeneous nucleation sites for silicide precipitates is beyond doubt and can be nicely related to structural configurations observed for early stages of homogeneous precipitation. Accumulation of dissolved metal impurities in or close to the dislocation core is an important process which needs further research, experimental and theoretical. First results point to a strong binding of metal atoms to the core of partial dislocations, an observation which has far-reaching consequences for gettering of metal impurities from dislocated silicon such as typical multicrystalline materials for photovoltaics. Theory further predicts a negative U-like level ordering for metal atoms in the dislocation core; experimental confirmation is lacking so far. Minority carrier recombination at dislocations is consistently described by the concerted action of shallow 1D bands, which are an intrinsic property of dislocations, and deep levels at or close to the dislocation core which seemingly are related to a large extent to impurities. It is interesting to note and of practical relevance that accumulation of impurities is advantageous over a complete dispersion for high contamination levels, but the opposite is true at low impurity concentrations.

Acknowledgements The authors are grateful to D. Abdelbarey, O. Voß, C. Rudolf, P. Saring, and L. Stolze for critical reading. We cordially thank the latter three for providing results prior to publication (Sect. 3.4). This work was financially supported by the Volkswagen foundation (SOBSI project) and by the German Federal Ministry for the Environment, Nature Conservation and Nuclear Safety and all the industry partners within the research cluster SolarFocus (0327650 B). The content of this publication is the responsibility of the authors.

\section{References}

1. R.M. Swanson, Prog. Photovolt. Res. Appl. 14, 443 (2006)

2. V. Kveder, M. Kittler, W. Schröter, Phys. Rev. B 63, 115208 (2001)

3. W. Schröter, H. Cerva, Solid State Phenomena 85-86, 67 (2002)

4. S.M. Myers, M. Seibt, W. Schröter, J. Appl. Phys. 88, 3795 (2000)

5. M. Seibt, V. Kveder, W. Schröter, O. Voß, Phys. Status Solidi A 202, 911 (2005)

6. M. Kittler, J. Lärz, W. Seifert, M. Seibt, W. Schröter, Appl. Phys. Lett. 58, 911 (1991)

7. M. Seibt, W. Schröter, Philos. Mag. 59, 337 (1989)

8. M. Seibt, H. Hedemann, A.A. Istratov, F. Riedel, A. Sattler, W. Schröter, Phys. Status Solidi A 171, 301 (1999)

9. W. Schröter, M. Seibt, D. Gilles, in Handbook of Semiconductor Technology, ed. by K.A. Jackson, W. Schröter, vol. 1 (Wiley, New York, 2000), p. 597

10. F. Riedel, W. Schröter, Phys. Rev. B 62, 7150 (2000)

11. P.S. Plekhanov, T.Y. Tan, Appl. Phys. Lett. 76, 3777 (2000)

12. P. Formanek, M. Kittler, J. Appl. Phys. 97, 063707 (2005)

13. T. Buonassisi, A.A. Istratov, M.D. Pickett, M. Heuer, J.P. Kalejs, G. Hahn, M.A. Marcus, B. Lai, Z. Cai, S.M. Heald, T.F. Ciszek, R.F. Clark, D.W. Cunningham, A.M. Gabor, R. Jonczyk, S. Narayanan, E. Sauar, E.R. Weber, Prog. Photovolt. 14, 513 (2006)

14. H. Alexander, H. Teichler, in Handbook of Semiconductor Technology, ed. by K.A. Jackson, W. Schröter, vol. 1 (Wiley, New York, 2000), p. 338

15. J. Rabier, P. Cordier, J.L. Dement, H. Garem, Mater. Sci. Eng. A 309-310, 74 (2001)

16. N. Lehto, S. Marklund, W. Yong-Liang, Solid State Commun. 92, 987 (1994)

17. F.D. Wöhler, H. Alexander, W. Sander, J. Phys. Chem. Solids 31, 1381 (1970)

18. V.A. Grazhulis, Yu.A. Osipian, Sov. Phys. JETP 31, 677 (1970) 
19. V.V. Kveder, Yu.A. Osipian, M.N. Zolotukhin, Sov. Phys. JETP 53, 160 (1981)

20. V. Kveder, T. Sekiguchi, K. Sumino, Phys. Rev. B 51(23), 16721 (1995)

21. V.V. Kveder, Yu.A. Ossipian, I.R. Sagdeev, A.I. Shalynin, M.N. Zolotukhin, Phys. Status Solidi A 87, 657 (1985)

22. M. Brohl, H. Alexander, in Structure and Properties of Dislocations in Semiconductors, ed. by S.G. Roberts, D.B. Holt, P.R. Wilshaw, IOP Conf. Proc. No. 104, Institute of Physics, London, 1989 , p. 163

23. A. Castaldini, D. Cavalcoli, A. Cavallini, S. Pizzini, Phys. Rev. Lett. 95, 076401 (2005)

24. M. Kittler, C. Ulhaq-Bouillet, V. Higgs, J. Appl. Phys. 78, 4573 (1995)

25. V. Higgs, M. Kittler, Appl. Phys. Lett. 65, 2804 (1994)

26. M. Kittler, W. Seifert, Scanning Microsc. 15, 316 (1993)

27. M. Kittler, W. Seifert, V. Higgs, Phys. Status Solidi A 137, 327 (1993)

28. K. Knobloch, M. Kittler, W. Seifert, J.J. Simon, I. Perichaud, Solid State Phenomena 63-64, 105 (1998)

29. S. Kusanagi, T. Sekiguchi, B. Shen, K. Sumino, Mater. Sci. Technol. 11, 685 (1995)

30. B. Shen, T. Sekiguchi, K. Sumino, Jpn. J. Appl. Phys. 35, 3301 (1996)

31. N. Fujita, R.J. Söberg, P.R. Briddon, A.T. Blumenau, Solid State Phenomena 131-133, 259 (2008)

32. W. Schröter, Phys Status Solidi A 19, 159 (1973)

33. A. Ourmazd, Cryst. Res. Technol. 16, 137 (1981)

34. P.R. Wilshaw, G.R. Booker, Inst. Phys. Conf. Ser. 76, 329 (1985)

35. R. Labusch, J. Phys. 40, 681 (1979)

36. R. Labusch, J. Phys. Condens. Matter 14, 12801 (2002)

37. W. Schröter, J. Kronewitz, U. Gnauert, F. Riedel, M. Seibt, Phys. Rev. B 52, 13726 (1995)

38. W. Schröter, H. Hedemann, V. Kveder, F. Riedel, J. Phys. Condens. Matter 14, 13047 (2002)

39. V.V. Kveder, Yu.A. Osipian, W. Schröter, G. Zoth, Phys. Status Solidi A 72, 701713 (1982)

40. P. Omling, E.R. Weber, L. Montelius, H. Alexander, J. Michel, Phys. Rev. B 32, 6571 (1985)

41. V. Kveder, V. Orlov, M. Khorosheva, M. Seibt, Solid State Phenomena 131-133, 175 (2008)

42. J.R. Patel, L.C. Kimerling, J. Phys. 40, 667 (1979)

43. P. Omling, E.R. Weber, L. Montelius, H. Alexander, J. Michel, Phys. Rev. B 32, 6571 (1985)

44. D. Cavalcoli, A. Cavallini, E. Gombia, Phys. Rev. B 56, 10208 (1997)

45. V. Kveder, W. Schröter, M. Seibt, A. Sattler, Solid State Phenomena 82-84, 361 (2002)

46. D. Maroudas, R.A. Brown, J. Appl. Phys. 69, 3865 (1991)

47. O.V. Kononchuk, V.V. Nikitenko, V.I. Orlov, E.B. Yakimow, Phys. Status Solidi A 143, K5 (1994)

48. O. Kononchuk, V. Orlov, O. Feklisova, E. Yakimov, Solid State Phenomena 51-52, 15 (1996)

49. R. Bullough, R.C. Newman, Prog. Semicond. 7, 100 (1963)

50. K. Knobloch, M. Kittler, W. Seifert, J. Appl. Phys. 93, 21069 (2003)

51. O. Voß, V.V. Kveder, W. Schröter, M. Seibt, Phys. Status Solidi C 6, 1847 (2005)

52. O. Voß, V. Kveder, M. Seibt, Phys. Status Solidi A 204, 2185 (2007)

53. A. Rodriguez, H. Brachta, I. Yonenaga, J. Appl. Phys. 95, 7841 (2004)

54. M. Seibt, A. Sattler, C. Rudolf, O. Voß, V. Kveder, W. Schröter, Phys. Status Solidi A 203, 696 (2006)

55. V. Kveder, M. Badylevich, W. Schröter, M. Seibt, E. Steinman, A. Izotov, Phys. Status Solidi A 202, 901 (2005)
56. V. Kveder, M. Badylevich, E. Steinman, A. Izotov, M. Seibt, W. Schröter, Appl. Phys. Lett. 84, 2106 (2004)

57. M. Östling, C. Zaring, in Properties of Metal Silicides, ed. by K. Maex, M. van Rossum (emis data review series No.14, INSPEC, London 1995), p. 31

58. D.R. Hamann, Phys. Rev. Lett. 60, 313 (1988)

59. V.J. Chabal, D.R. Hamann, J.E. Rowe, M. Schlüter, Phys. Rev. B 25, 7598 (1982)

60. J. Tersoff, D.R. Hamann, Phys. Rev. B 28, 1168 (1983)

61. K.A. Mäder, H. von Känel, Phys. Rev. B 48, 4364 (1993)

62. N.E. Christensen, Phys. Rev. B 42, 7148 (1990)

63. N. Cherief, C. D'Anterroches, R.C. Cinti, T.A. Nguyen Tan, J. Derrien, Appl. Phys. Lett. 55, 1671 (1989)

64. J.W. Christian, The Theory of Transformation in Metals and Alloys (Pergamon, Elmsford, 1975), p. 437

65. R. Wagner, R. Kampmann, in Handbook of Materials Science and Technology, vol. 5, ed. by R.W. Cahn, P. Haasen, E.J. Kramer (VCH, Weinheim, 1991), p. 212

66. W. Schröter, M. Seibt, in: Properties of Crystalline Silicon, ed. by R. Hull, The Institute of Electrical Engineering 1999, pp. 543 and 561

67. J. Utzig, J. Appl. Phys. 65, 3868 (1989)

68. A.A. Istratov, H. Hieslmair, E.R. Weber, Appl. Phys. A 69, 13 (1999)

69. M. Seibt, in Semiconductor Silicon 1990, ed. by H.R. Huff, Y. Takeshi, W. Bergholz (The Electrochemical Society, Pennington, 1990), p. 663

70. M. Seibt, Solid State Phenomena 19-20, 45 (1991)

71. M. Seibt, A. Griess, A.A. Istratov, H. Hedemann, A. Sattler, W. Schröter, Phys. Status Solidi A 166, 171 (1998)

72. E. Nes, J. Washburn, J. Appl. Phys. 42, 3562 (1971)

73. O.F. Vyvenko, Solid State Phenomena 63-64, 301 (1998)

74. A. Sattler, H. Hedemann, A.A. Istratov, M. Seibt, W. Schröter, Solid State Phenomena 63-64, 369 (1998)

75. R. Khalil, V. Kveder, W. Schröter, M. Seibt, Solid State Phenomena 108-109, 109 (2004)

76. R. Khalil, V. Kveder, W. Schröter, M. Seibt, Phys. Status Solidi C 2, 1802 (2005)

77. M.G. Wardle, J.P. Goss, P.R. Briddon, R. Jones, Phys. Status Solidi A 202, 883 (2005)

78. W. Schröter, H. Hedemann, V. Kveder, F. Riedel, J. Phys. Condens. Matter 14, 13047 (2002)

79. H. Hedemann, W. Schröter, Solid State Phenomena 57-58, 293 (1997)

80. M.V. Trushin, O.F. Vyvenko, Phys. Status Solidi C 4, 3056 (2007)

81. A.A. Istratov, H. Hedemann, M. Seibt, O.F. Vyvenko, W. Schröter, T. Heiser, C. Flink, H. Hieslmair, E.R. Weber, J. Electrochem. Soc. 145, 3889 (1998)

82. C. Flink, H. Feick, S.A. McHugo, W. Seifert, H. Hieslmair, T. Heiser, A.A. Istratov, E.R. Weber, Phys. Rev. Lett. 85, 4900 (2000)

83. J.J. van Kooten, E.G. Sieverts, C.A.J. Ammerlaan, Solid State Commun. 64, 1489 (1987)

84. S.H. Muller, G.M. Tuymann, E.G. Sieverts, C.A.J. Ammerlaan, Phys. Rev. B 25, 25 (1982)

85. H. von Känel, K.A. Mäder, E. Müller, M. Onda, H. Sirringhaus, Phys. Rev. B 45, 13807 (1992)

86. N. Onda, J. Henz, E. Müller, K.A. Mäder, H. von Känel, Appl. Surf. Sci. 56-58, 421 (1992)

87. M.G. Grimaldi, P. Baeri, C. Spinella, S. Lagomarsino, Appl. Phys. Lett. 60, 1132 (1992)

88. R.L. Maltez, M. Behar, X.W. Lin, Nucl. Instrum. Methods Phys. Rev. B 106, 400 (1995)

89. Y. Gao, S.P. Wong, W.Y. Cheung, G. Shao, K.P. Homewood, Appl. Phys. Lett. 83, 638 (2003) 
90. M. Seibt, K. Graff, J. Appl. Phys. 63, 4444 (1989)

91. A.G. Cullis, L.E. Katz, Philos. Mag. 30, 1419 (1974)

92. K. Honda, A. Ohsawa, N. Toyokura, Appl. Phys. Lett. 45, 270 (1984)

93. J. Wong-Leung, D.J. Eaglesham, J. Sapjeta, D.C. Jacobson, J.M. Poate, J.S. Williams, J. Appl. Phys. 83, 580 (1998)

94. M. Seibt, unpublished results

95. J.M. Silcock, W.J. Tunstall, Philos. Mag. 10, 361 (1964)

96. E. Nes, Acta. Metall. 22, 81 (1974)

97. J.K. Solberg, Acta Crystallogr. A 34, 684 (1978)

98. A. Broniatowski, Phys. Rev. Lett. 63, 3074 (1989)

99. M. Kittler, C. Ulhaq-Bouillet, V. Higgs, J. Appl. Phys. 78, 4573 (1995)

100. M. Kittler, W. Seifert, Mat. Sci. Forum 196-201, 1123 (1995)

101. M. Seibt, Mat. Res. Soc. Symp. Proc. 262, 957 (1992)

102. W.C. Dash, J. Appl. Phys. 27, 1193 (1956)

103. H. Ewe, D. Gilles, S.K. Hahn, M. Seibt, W. Schröter, in Semiconductor Silicon, ed. by H.R. Huff, W. Bergholz, K. Sumino (The Electrochemical Society, Pennington, 1994), p. 796

104. H. Ewe, Ph.D. Thesis, Göttingen, 1996

105. M. Seibt, V. Kveder, Solid State Phenomena 95-96, 447 (2004)

106. A.A. Istratov, T. Buonassisi, R.J. McDonald, A.R. Smith, R. Schindler, J.A. Rand, J.P. Kalejs, E.R. Weber, J. Appl. Phys. 94, $6552(2003)$
107. M. Setton, in Properties of Metal Silicides, ed. by K. Maex, M. van Rossum (emis data review, series No. 14, INSPEC, London, 1995), p. 129

108. E.M. Sokolovskaya, O.I. Chernikova, E.I. Gladyshevsky, O.I. Bodak, Russ. Metall. 6, 114 (1973). Translated from Izv. Nauk SSSR Met.

109. T. Buonassisi, M. Heuer, A.A. Istratov, M.D. Pickett, M.A. Marcus, B. Lai, Z. Cai, S.M. Heald, E.R. Weber, Acta Mater. 55, 6119 (2007)

110. M. Heuer, T. Buonassisi, M.A. Marcus, A.A. Istratov, M.D. Pickett, T. Shibata, E.R. Weber, Phys. Rev. B 73, 235204 (2006)

111. M. Heuer, T. Buonassisi, A.A. Istratov, M.D. Pickett, M.A. Marcus, A.M. Minor, E.R. Weber, J. Appl. Phys. 101, 123510 (2007)

112. H. Nordmark, M. Di Sabatino, E.J. Øvrelid, J.C. Walmsley, R. Holmestad, Proceedings of 22nd EUPVSEC, 3-7 Sept. 2007 Milan, Italy, p. 1710

113. C. Rudolf, P. Saring, L. Stolze, M. Seibt, Mater. Sci. Eng. B, in press

114. P. Saring, C. Rudolf, L. Stolze, M. Seibt, Mater. Sci. Eng. B, in press 